Working Paper 02-27

Economics Series 08

June 2002
Departamento de Economía Universidad Carlos III de Madrid

Calle Madrid, 126

28903 Getafe (Spain)

Fax (34) 916249875

\title{
MODELING ELECTRICITY PRICES: INTERNATIONAL EVIDENCE *
}

\author{
Álvaro Escribano ${ }^{1}$, Juan Ignacio Peña ${ }^{2}$ and Pablo Villaplana ${ }^{3}$
}

\begin{abstract}
This paper analyses the evolution of electricity prices in deregulated markets. We present a general model that simultaneously takes into account the possibility of several factors: seasonality, mean reversion, GARCH behaviour and time-dependent jumps. The model is applied to equilibrium spot prices of electricity markets from Argentina, Australia (Victoria), New Zealand (Hayward), NordPool (Scandinavia), Spain and U.S. (PJM) using daily data. Six different nested models were estimated to compare the relative importance of each factor and their interactions. We obtained that electricity prices are mean-reverting with strong volatility (GARCH) and jumps of time-dependent intensity even after adjusting for seasonality. We also provide a detailed unit root analysis of electricity prices against mean reversion, in the presence of jumps and GARCH errors, and propose a new powerful procedure based on bootstrap techniques.
\end{abstract}

Keywords: electricity prices, seasonality, mean reversion, GARCH, jumps, unit root test, bootstrap.

JEL Clasification: C22, L94, L9 and G10

1 Departamento de Economía, Universidad Carlos III de Madrid, Spain; E.mail: alvaroe@eco.uc3m.es

2 Departamento de Economía de la Empresa, Universidad Carlos III de Madrid, Spain; E.mail: ypenya@eco.uc3m.es

Departamento Economía de la Empresa, Universidad Carlos III de Madrid, Spain; E.mail: villapla@eco.ucm.es

\footnotetext{
* The authors are grateful to the comments received on the first version of this paper from Angel Leon, Craig Pirrong, Cristopher R. Knittel, Michael Roberts and the participants at the I Workshop in Electricity Derivatives (Valencia, Spain), IX Foro Finanzas (Pamplona, Spain), EFA (Berlin) and EARIE (Madrid). We acknowledge financial support provided by DGYCIT grant PB98-0030. P. Villaplana also acknowledges financial support provided by Energy Economics Laboratory, of the Universidad Carlos III de Madrid.
} 


\section{INTRODUCTION}

Until early 90's the electricity sector has been a vertically integrated industry, where regulators fixed prices as a function of generation, transmission and distribution costs and therefore there was little uncertainty in prices. In last years electricity markets in many countries are experiencing a deregulation process, with the aim of introducing competition in generation and supply activities (not in transmission and distribution since they are considered natural monopolies). One of the main consequences of this reform is that prices are determined by the interaction between supply (generators) and demand (suppliers, who are agents that buy energy and sell it to the consumers) in what is usually called a "pool". In this context generators compete to sell electricity in the market pool while the suppliers to consumers purchase electricity from the pool at equilibrium prices set by the intersection of aggregated demand and supply on an hourly (or half-hourly) basis. These new deregulated prices have been characterized in all the markets by having an extremely high volatility. Even when compared with financial markets (stock, bonds) or with other commodities, the behavior of electricity prices is still regarded as quite complex and volatile. The deregulation has introduced new elements of uncertainty in the sector and therefore usual financial aspects like financial risk management, derivative contracts, or hedging are being introduced in the industry. In fact the more experienced markets now include futures and options markets (for instance, electricity futures contracts are traded in different markets, Sidney Futures Exchange, New Zealand Futures and Options Exchange, Eltermin (Scandinavia), NYMEX and others). There is an extensive literature on the deregulation effects of electricity markets from a regulatory and industrial organization point of view. For an introduction to the analysis of competition in electricity markets, see for instance, Wolak(1997), Hogan (1998), Borenstein (2001) and references therein.

The characterization and understanding of the behavior of electricity prices is a necessary task and is the basis for the valuation and risk management of real assets and financial claims on the commodity. Some initial recent contributions are Johnson and Barz (1999), Bhanot (2000), Lucia and Schwartz (2002) and Knittel and Roberts (2001).

We extend this literature by proposing and estimating a general and flexible model and applying it to a comprehensive set of markets, Argentina, NordPool, Australia (Victoria), New Zealand (Hayward), US (Pennsylvania-New Jersey-Maryland, PJM hereafter) and Spain. This will allow us to compare the different behavior observed in deregulated markets and quantify the role of different characteristics (importance of seasonality, mean-reversion, volatility and/or jumps) in each individual market. Our goal is to propose a general (benchmark) model that encompasses the main features present in all markets.

One of the main innovations of this paper is the estimation of a general and flexible model to a comprehensive set of markets. That is, we take into account the interaction between jumps and GARCH behavior, and among jumps, GARCH and mean reversion. Our results stress the importance of including those three elements simultaneously in order to isolate the main elements of the behavior of electricity prices in deregulated markets. The other main contribution is the proposal and application of a new unit root testing strategy in the presence of jumps and volatility. Although we focus on equilibrium prices from electricity 
markets, this modeling strategy could also be applied to other commodity prices like for instance, natural gas.

The paper is organized as follows. Section 2 describes the main characteristic factors of electricity prices and discuss some related literature. Section 3 presents the model and the econometric methodology. Section 4 describes our data sets and presents some descriptive statistics. Section 5 presents the empirical results from the estimated models. Section 6 applies a variety of unit root tests for the null hypothesis of a unit root against the alternative of mean reversion. Finally, section 7 includes some conclusions and provides some insights for future risk management research based on our empirical findings.

\section{ELECTRICITY PRICE BEHAVIOR AND RELATED LITERATURE}

\subsection{Why are electricity prices so volatile?}

There are several elements that explain the observed high volatility of electricity prices. Probably the most important one is the non-storability of electricity. Electricity cannot be physically stored in a direct way (electricity can be indirectly stored via hydroelectric schemes or via storage of generator fuel), and production and consumption have to be continuously balanced. Therefore, supply and demand shocks cannot easily be smoothed out and they will have a direct effect on equilibrium prices.

The characteristics of demand and supply play also an important role in the observed volatility. Electricity demand is highly inelastic because it is a necessary commodity and also highly weather-dependent. The characteristics of the supply stack of each market can also contribute to the volatility of a particular demand. Pool's prices are determined by the intersection between demand and supply. For low levels of demand, generators supply electricity by using base-load units with low marginal costs, as higher quantities are needed new generators with higher marginal costs enter into the system. The relative insensitivity of demand to price fluctuations and the binding constraints supply can face at peak times, makes short-term prices for electricity extremely volatile. Therefore, in markets where both the demand and supply curves are steep we could observe sharp increases in prices as the quantity demanded is increased. Moreover, depending on the structure of the market and the market power of the gnerators, for high levels of demand only few generators could satisfy the residual demand and therefore market power could come into play through monopolistic or oligopolistic behaviors of generators.

\subsection{Characteristics of electricity prices}

The model we propose is very flexible and allow us to simultaneously include seasonality, mean reversion, volatility and jumps. The main goal of this paper is to show that this general model captures the salient idiosyncratic features of electricity prices. As we will see later on in sections 4 and 5 , there is enough empirical evidence in the data to include the four characteristics simultaneously.

\subsubsection{Seasonality}

Electricity demand is heavily influenced by economic and business activities and by the weather conditions. These two factors explain the main seasonal behavior of electricity prices. Different kinds of seasonality appear in the data; intra-daily, weekly and monthly seasonality. As it is usual in this literature, we assume that seasonality is generated by deterministic factors and since we use the average daily prices, we 
will only consider weekly and monthly seasonality. In particular, the seasonality is captured by means of two deterministic seasonal functions: a) weekly seasonality, captured by means of daily dummies and b) monthly seasonality, captured by either monthly dummies or by a sinusoidal functions.

The importance of deterministic regular patterns in the behavior of electricity prices has been analyzed by Lucia and Schwartz (2002) and by Bhanot (2000). Lucia and Schwartz (2002) propose and estimate a one and two-factor mean reverting models with deterministic seasonality for the Scandinavian market (NordPool), showing that the seasonal pattern in spot electricity prices could explain part of the shape of the observed term structure of futures prices. Bhanot (2000) analyses electric power prices using data from 12 regional markets from the US focusing in the mean-reverting and seasonal behavior of the series and on the possible regional differences among them.

\subsubsection{Mean-reversion}

Since shifts in demand will push prices up, increasing the economic incentives of more expensive generators to enter in the supply side (shift in supply) of the system, it seems natural to expect some degree of mean reversion in the evolution of electricity prices. On the other hand, it could also be argued that prices are mean-reverting because weather is a dominant factor which influences equilibrium prices through changes in demand. Since the evolution of weather is a cyclical and mean-reverting process, this tendency to revert to its mean level (maybe time-varying) will affect demand and therefore also equilibrium prices (Knittel and Roberts 2001). Although the great majority of models have been proposed up to now are meanreverting models, for instance, Bhanot (2000), Karesen and Husby (2000), Lucia and Schwartz (2002) and Knittel and Roberts (2001) there are also some recent papers that characterize electricity prices as non-mean reverting, see for example De Vany and Walls (1999) and Leon and Rubia (2001). Furthermore, Johnson and Barz (1999) analyzed the fit of mean-reverting and non-mean reverting models with and without jumps to a set of deregulated markets. They found that the best fit was obtained by a mean-reverting model with jumps. However they did not provide any formal test (unit roots, etc.) nor considered the possibility of non-constant volatility (GARCH, etc.). In this paper we solve those limitations in two ways: a) extending the analysis to electricity markets for other countries and b) suggesting a new formal procedure to tests for the unit root hypothesis against the alternative of mean-reversion in the presence of GARCH and Jumps in the data.

\subsubsection{Jumps and volatility}

By simple eye inspection (a formal econometric analysis will be done in Section 5) of the graphs presented in Figures 1 to 6 of the appendix, it is clear the existence of important jumps in the behavior of electricity prices.

One of the characteristics of evolution of these jumps is that the price does not stay in the new level, to which it jumps, but reverts to the previous level rapidly. This behavior can be captured by introducing a Poisson process as in a jump-diffusion model. There are already some applications of jump-diffusions to electricity prices. Johnson and Barz (1999) estimate various jump-diffusion process to several electricity price series, Knittel and Roberts (2001) also estimate a jump diffusion model (with time dependent jump intensity) to California prices. In spite of the advantages of introducing jumps in the model there are some limitations in modelling electricity prices by jump-diffusion processes (see e.g. Pirrong and Jermakyan 1999 
and Clewlow and Strickland 2000). The main criticism is the assumption that all the shocks affecting the series die out at the same rate. Simple economic intuition would argue that this is not a likely case. For larger shocks it seems evident that forces of demand and supply will push back electricity prices quite fast. On the other hand, when shocks are smaller it is more likely that prices will revert slowly to the previous level due to the existence of adjustment costs. In statistical terms, modeling the series by a jump diffusion process has its own limitations. When estimating the jump-diffusion process by (Quasi) Maximum Likelihood the estimated model tend to capture the smallest and more frequents jumps in the data. Furthermore, the jumpdiffusion modeling approach does not capture the fact that jumps will probably appear in those periods where the difference between the maximum supply and the demand is not very big (small excess capacity). If the supply stack is convex (increasing marginal costs) during periods of high demand, the effect on prices, for a given increase in demand (shift of the demand curve to right), will be greater the smaller is the excess capacity. Our flexible modeling approach solves those limitations.

Another important aspects of electricity prices is the existence of high volatility and volatility clustering. One of the most popular approaches for modeling conditional volatility is the GARCH model and its extensions. Although there is some work on applying models of the ARCH family to electricity prices there are problems with the usual modeling approach. For an application of different types of ARCH or GARCH models to energy prices see Duffie et al. (1998) and Knittel and Roberts (2001). Duffie et al. (1998) showed that the application of these kind of models to electricity prices has its limitations, because one can end with an integrated volatility process, which is not a very appealing result. One of the reasons for the possibility of explosive volatility is the presence of outliers (spikes) in the data, biasing the estimation of the GARCH process. This bias of GARCH coefficients in the presence of jumps has also been obtained in other financial applications, see for instance the application of jump-diffusions to exchange rates belonging to the ERM, Neely (1999). Other papers that analyze the effects of outliers (jumps) on GARCH models with applications to stock data are Carnero, Peña and Ruiz (2001), Hotta and Tsay (1998) and Verhoeven and McAleer (2000). Our results show that one can improve both jump-diffusion models and GARCH models by working with a model that simultaneously takes into account both characteristics. We show that both modeling approaches are complementary and not substitutes. It is remarkable that once we allow for jumps in the GARCH models we recover the desired stationarity of the volatility process. On the other hand, by allowing a GARCH behavior in the jump-diffusion process we find a decreasing probability of observing a jump since part of the smaller jumps that were previously captured by the pure jump model are now part of the GARCH component.

Furthermore, we allow for non-constant jump intensities. We have seen that the technological characteristics of electricity markets, like increasing marginal costs in the supply stack, increase the probability of observing higher jumps when demand is high (high rate of capacity utilization), see for instance Birnbaum et al. (2002). However, we also observe jumps in electricity prices even when demand is not very high. This is in general due to transmission problems or because certain plants cannot generate electricity. In those situations, the decrease (shift to the left) in supply and not the increase in demand, is the alternative main source of jumps of equilibrium prices. For illustrative purposes and data limitations, we have decided to model the time 
varying specification of the jump intensity by introducing different dummies per season. These dummies are proxies for the demand variable that is one of the main sources of observed jumps. It is worth noting the flexibility of our model allowing for simultaneous modeling of intensity of the jump process and volatility (GARCH).

\section{MODEL SPECIFICATION AND ESTIMATION}

We have seen in previous section that a reasonable model for electricity prices should allow for the existence of deterministic seasonality, the possibility of mean-reversion, jumps and (stochastic) volatility. Therefore we propose a model that simultaneously incorporates all these factors in an flexible way. In particular, our general model takes into account the possibility of seasonality (deterministic), meanreversion, volatility (GARCH behavior) and jumps (with the possibility of time-dependent intensity). Moreover we can test for the significance of each of these factors, estimating six different nested models for each of the analyzed markets.

We present the model in continuous and discrete time. Since this paper is devoted to the analysis of the data generating process of equilibrium spot electricity prices, we work with the discrete time version of the model. But since most financial questions (for instance valuation and hedging) are usually addressed in continuous time we first present the model in its continuous time version.

The model in continuous time is ${ }^{1}$ :

$$
\begin{gathered}
P_{t}=f(t)+X_{t} \\
d X_{t}=-\kappa X_{t} d t+v_{t}^{1 / 2} d Z+J\left(\mu_{J}, \sigma_{J}\right) d \prod\left(\lambda_{t}\right) \\
d v_{t}=k_{v}\left(\theta_{v}-v_{t}\right) d t+v_{t}^{1 / 2} \sigma d Z_{v}
\end{gathered}
$$

where $P_{t}$ is the equilibrium spot electricity price of electricity markets, $f(t)$ is a deterministic seasonal function that captures the seasonality observed in electricity prices (captured either by monthly dummy variables or by sinusoidal functions), $d Z$ and $d Z_{v}$ are independent Wiener processes, $d \prod\left(\lambda_{t}\right)$ is a Poisson distributed random variable with (time-dependent) intensity $\lambda_{t}$, and $J\left(\mu_{J}, \sigma_{J}\right)$ is a random variable normally distributed with mean $\mu_{J}$ and standard deviation $\sigma_{J} . v_{t}$ captures the evolution of the stochastic volatility. We assume that the Wiener processes, the Poisson process and the jump size are mutually independent processes.

Continuous-time models are the basis for a wide range of problems in finance and are usually hard to estimate. The estimation methods for continuous-time models are computationally intensive in practice and they are specially difficult to estimate in the context of time dependent intensities. A popular approach has been discretization (for instance using the Euler approximation). It is well known that discretization of continuous-time stochastic differential equations does introduce an estimation bias. However, the bias is smaller the shorter the sampling interval. With daily data this bias is negligible (see Bergstrom 1988, Melino 1994 and Das 2001).

\footnotetext{
${ }^{1}$ Notice that we are dealing with equilibrium electricity prices. The data we use is the average price. We have decided not to take logarithms since this transformation would tend to eliminate right skewness and outliers. In our case right skewness and outliers are explicitly modelled as part of the main sources of uncertainty.
} 
The goal of this paper is to disentangle the possible components that are present in electricity prices series and therefore, we have decided to work with a discrete time version of model (1)-(3) for two reasons: a) the estimation bias with daily data is negligible and $b$ ) we have greater flexibility with discrete time models. The general discrete time model we estimate is:

$$
\begin{gathered}
P_{t}=f(t)+X_{t} \\
X_{t}=\left\{\begin{array}{cc}
\phi X_{t-1}+h_{t}^{1 / 2} \varepsilon_{l t} ; & \text { prob. } 1-\lambda_{t} \\
\phi X_{t-1}+h_{t}^{1 / 2} \varepsilon_{l t}+\mu_{J}+\sigma_{J} \varepsilon_{2 t} ; & \text { prob. } \lambda_{t} \\
h_{t}=\omega+\alpha \varepsilon_{t-1}^{2}+\beta & h_{t-1} \\
\lambda_{t}=L 1 \cdot \text { winter }_{t}+L 2 \cdot \text { fall }_{t}+L 3 \cdot \text { spring }_{t}+\text { LA summer }
\end{array}\right.
\end{gathered}
$$

where $\varepsilon_{1 t}$ and, $\varepsilon_{2 t} \sim$ i.i.d. $N(0,1)$. The parameter $\phi$ describes the degree of mean-reversion, if $|\phi|<1$, then $P_{t}$ reverts back to its (non-constant) mean. The parameter $\phi$ in (5) stands for (1-K) in (2), so a low mean reversion, low $\kappa$ is equivalent to $\phi \approx 1$. The (nonnegative) parameters $\omega, \alpha$ and $\beta$ characterize the dynamics of the volatility following a $\operatorname{GARCH}(1,1)$ process $(\omega>0 ; \alpha, \beta \geq 0)$. The nonegativity restrictions are needed to guarantee that the conditional variance is positive and also $\omega$ has to be strictly positive for the process not to degenerate. If $\alpha+\beta<1$, then the variance reverts back to its unconditional mean $\sigma^{2}=\omega /(1-\alpha-\beta)$.

The equation (7) models the time-dependent intensity process for the jumps by means of three dummies; winter $_{t}$ is a dummy variable that takes value 1 if the observation is in December, January and February and zero otherwise; fall $t_{t}$ takes value 1 if the observation is in September, October or November and zero otherwise; spring $_{t}$ takes value 1 if the observation is in March, April or May and zero otherwise and finally summer $_{t}$ takes value 1 if the observation is in June, July or August and zero otherwise.

The deterministic seasonality is specified either by monthly dummy variables or by sinusoidal functions. However, for space reasons and to avoid a tedious reading, we only provide the results of the sinusoidal specification since the results are very similar with both specifications. In particular, with sinusoidal functions the seasonal factor is specified as:

$$
f(t)=B 0+B 2 \cdot t+C 1 \cdot \sin (t+C 2)(2 \pi / 365))+C 3 \cdot \sin ((t+C 4)(4 \pi / 365))+D 1 \cdot w k d_{t}
$$

where $w k d_{t}$ is a dummy variable that takes value 1 if the observation is in weekday and zero otherwise (weekend). With this general formulation for the sinusoidal function we allow for the possibility of having two cycles per year (two local maximum per year). In the case of one annual cycle we should have $C 3=C 4$ $=0$. 
By comparing different restricted versions of model (4)-(8) we are able to check which kind of model better explains the evolution of electricity prices. Since the proposed model is quite flexible we should be able to explain equilibrium electricity prices with higher or lower levels of kurtosis, greater or smaller relative importance of spikes, etc.

The simultaneous modeling of GARCH and jump components in electricity markets is an important extension. The question of whether jump processes or stochastic volatility better describe the evolution of prices giving the observed kurtosis has produced and ongoing debate in financial modeling (Das and Sundaram 1997, Das 2001). The sampling interval used in empirical applications also has its role in deciding which approach must be followed. See the discussion and the test statistic proposed by Das (2001) to decide between stochastic volatility and jumps. Our results show that both sources of uncertainty are complementary rather than substitutes, although the relative contribution of each component is different in each market.

The set of parameters is $\Theta=\left\{f(t), \phi, \sigma^{2}, \omega, \alpha, \beta, \mu_{J}, \sigma_{J}{ }^{2}, \lambda_{t}\right\}$ is estimated by Maximum Likelihood (ML). Estimation of $\Theta$ involves the following maximization:

$$
\operatorname{Max}_{\Theta} \Sigma_{\mathrm{t}=1}^{\mathrm{T}}\left(\log \left(f\left[p_{t} \mid p_{t-1}\right]\right)\right)
$$

Contingent on the particular nested specification considered some parameters from equation (10) will be set equal to zero. Now, consider that the transition probabilities for electricity equilibrium prices follows a Poisson-Gaussian process. That is,

$$
\begin{aligned}
& f\left[p_{t} \mid p_{t-1}\right]=\lambda_{t} \cdot \exp \left[\frac{-\left(p_{t}-f(t)-\phi \cdot p_{t-1}-\mu_{J}\right)^{2}}{2\left(h_{t}+\sigma_{J}^{2}\right)}\right] \frac{1}{\sqrt{2 \pi\left(h_{t}+\sigma_{J}^{2}\right)}} \\
& +\left(1-\lambda_{t}\right) \cdot \exp \left[\frac{-\left(p_{t}-f(t)-\phi \cdot p_{t-1}\right)^{2}}{2 h_{t}}\right] \frac{1}{\sqrt{2 \pi h_{t}}} .
\end{aligned}
$$

Equation (10) approximates the true Poisson-Gaussian density with a mixture of normal distributions. Other Poisson-Gaussian models could have been considered as was done in the context of exchange rates and interest rates. However, previous evidence shows that the mixture approximation leads to similar results and is much easier to estimate. For some applications to exchange rates see, Vlaar and Palm (1993), Nieuwland, Verschoor and Wolff (1994) and Neely (1999), and Das (2001) for interest rates.

In order to compare different processes for electricity prices we estimate six nested models on our international data set. For expository reasons, we have included the explicit formula of each model in Appendix B. The six models we estimate are: a pure-Gaussian model with constant variance and without jumps (Model 1); a GARCH(1,1)-Gaussian model without jumps (Model 2), a Poisson-Gaussian models with constant variance (Model 3), a Poisson-Gaussian models with time-varying intensity for jumps (Model 3b), a GARCH(1,1)-Poisson-Gaussian model with constant intensity (Model 4) and the most general model is a GARCH(1,1)-Poisson-Gaussian model with time-varying intensity for jumps (Model 4b). All of the models have been estimated by maximum likelihood using RATS 2.5. The parameters estimates were 
obtained using Berndt, Hall, Hall and Hausman (1974) algorithm. Reported results are robust to different starting values.

\section{DATA AND DESCRIPTIVE ANALYSIS}

\subsection{Data}

The electricity markets analyzed in this paper are: NordPool (Scandinavia), Argentina, Australia (Victoria), New Zeala nd (Hayward), PJM and Spain. We work with daily averages of electricity spot prices (on-peak and off-peak hours), so we have one price for each day. All the series are expressed in the local currency of the market. Data has been obtained from each of the pools. The sample period available is different in each international market ${ }^{2}$.

\subsection{Descriptive statistics.}

We present in Appendix A, a table (Table 1) with descriptive statistics for each of the five series. We may observe that price series are quite volatile, have positive skewness and high kurtosis. We may also see that although all of them share these characteristics there exist some differences among them. As was pointed out by Wolak (1997), the generation mix (supply stack) of each market will translate into the behavior of observed spot prices. In particular in Argentina and in Australia electricity is mainly generated by fossil fuel technology, while in New Zealand and NordPool electricity is mainly generated by hydroelectric sources. Therefore as seen in Table 1, the prices in the NordPool and New Zealand markets are less volatile than prices in Australia, Argentina and PJM. In fact we observe from the graphs of Victoria, Argentina and PJM equilibrium prices that spikes are quite important.

Wolak (1997) also pointed out the effect that regulation and market microstructure rules have on the behavior of electricity prices. Those effects are also crucial to understand the behavior of equilibrium electricity prices in Spain, see Federico and Whitmore (1999) and Fabra and Toro (2001). The differences between markets should, and in fact do, translate to the estimation results. For instance, as we have commented previously, those series with higher coefficient of kurtosis, tend to have in the GARCH $(1,1)$ model a higher estimated persistence. As we said above, GARCH models usually tend to introduce high persistence in the estimation in order to be able to generate a high degree of kurtosis. On the other hand, the degree of skewness translates in the estimated mean jump size. It can be shown that the mixture model generates higher skewness the bigger the mean jump size.

From the summary statistics of Table 1 and from the graphs of the price series we may see that the behavior of electricity prices in each market is quite different. This fact provides evidence on the high degree of regionalism of deregulated electricity markets. The existence of differences among market (for instance because differences in the type of generation, proportion of electricity generated by hydro, coal, gas or nuclear plants) supports the idea that we should approach the analysis of each market with a general flexible model, and that we should let data determine which are the most important idiosyncratic features of a given market.

\footnotetext{
${ }^{2}$ However, the bests models were re-estimated during common periods with similar results obtained. For consistency and efficiency reasons of the estimates we report the results obtained from the longest possible samples of each international market.
} 


\section{RESULTS}

In this section we highlight the main empirical results obtained, see Appendix B (Tables B.1 to B.6). Six models were estimated to each of the average daily prices of the five international markets in order to estimate the relative contribution of each of the main four temporal characteristics of electricity prices: seasonality, mean-reversion, non-constant volatility (GARCH) and jumps.

The selection between the two ways we model seasonality in electricity prices, monthly dummies or sinusoidal functions, is less relevant the more regular the seasonal pattern is. Dummy variables are more sensitive to the presence of jumps and they could in principle provide a higher modeling flexibility. However, since our empirical results are very similar with both procedures, we only report the results obtained with the sinusoidal function.

The mean-reverting property of electricity prices seems clear from the plots, see Figures 1 to 6 , or from the estimated models, see Appendix B. In all the models estimated, the autoregressive coefficient $\phi$ is positive and smaller than 1 . Only in the NordPool the estimated coefficient is close to 1 indicating a slow meanreversion. For example in Model 1 of Table B.1, $\phi=0.93$.

The low degree of mean-reversion observed in NordPool can be explained by the fact that in the Scandinavian market, electricity is mainly generated by hydro resources. Hydro reservoirs play the role of indirect storage of electricity, therefore in these type of markets we could expect more inter-temporal substitution between inputs than in markets with a low proportion of electricity generated by water. In markets with no inter-temporal substitution we should observe a higher degree of mean-reversion since generators cannot use inventories to smooth out shocks, and the degree of mean-reversion in electricity prices is mainly driven by the mean-reversion in demand or in temperature. On the contrary, New Zealand power generation is also driven by hydro resources and it has a high degree of mean-reversion. Wolak (1997) pointed out the fact that in markets dominated by hydroelectric power, average prices are less stable. This instability of mean prices is clearly observed in the NordPool case. For example, the fact that 1996 was a dry year, created a high mean levelof prices during that year, see also Lucia and Schwartz (2002).

This kind of weather instability reduces the estimated degree of mean-reversion in prices, generating a dynamic behavior in prices that is approximated by a unit root process with autoregressive conditional heteroskedastic errors. By comparing the estimated autoregressive coefficient $(\phi)$ of model 1 with models 2 to 4 we provide direct evidence on the effects of outliers and GARCH behavior on the unit root hypothesis. In particular, in the NordPool case when we include GARCH and jumps in the model, we clearly see that the mean reversion property becomes more apparent reducing the estimated value of $\phi$ from 0.93 to 0.8 . A formal unit root analysis against mean-reversion alternatives will be considered in section 6 .

The summary statistics of Appendix A and also the price plots of Figure 1 to 6 provide clear evidence on the volatility of electricity prices and in particular the non-constant and the clustering of the volatility. A wellknown cause of leptokurtosis in the unconditional distribution is conditional heterocedasticity, which supports the need to move beyond a simple constant variance Gaussian model. As expected, we obtain that Model 2 (that incorporates a GARCH(1,1) component) gives an important improvement in goodness of fit 
with respect to the constant variance of Model 1 in all of the five international markets analyzed. One important aspect of most electricity markets is that the empirical parameter estimates of the $\operatorname{GARCH}(1,1)$ models imply that the volatility process is explosive, i.e. $\alpha+\beta>1$, Bollerslev (1986). A common finding is that GARCH models tend to impute a high degree of persistence (quantified by $\alpha+\beta$ ) to the conditional volatility, generating a conditional variance process which is not covariance-stationary. Furthermore, since the $j$ th period ahead forecast of the conditional variance is given by:

$$
E\left(h_{t+j}\right)=\sigma^{2}+(\alpha+\beta)^{j}\left(h_{t}-\sigma^{2}\right), \text { for } j \geq 1
$$

when $\alpha+\beta=1$, shocks to the conditional variance accumulate and therefore are highly persistent, in the sense that $E\left(h_{t+j} \mid h_{t}\right) \rightarrow \infty$ as $j \rightarrow \infty$ see Nelson (1990), and when $\alpha+\beta>1$ the volatility forecast is explosive. It is clear that the explosive volatility forecast characteristic of electricity markets is not an appealing result since the predictions of the model are meaningless and create difficulties to do any possible risk management analysis based on prices from electricity markets.

In particular, this empirical result is obtained in Argentina, Australia and PJM electricity markets where the estimated GARCH have $\alpha+\beta>1$. This property could have been anticipated since there is a high degree of kurtosis of electricity prices. The close relationship between the degree of kurtosis generated by a $\operatorname{GARCH}(1,1)$ process and the value of $\alpha+\beta$ is well known, see for instance Carnero, et al. (2002). In the GARCH $(1,1)$ processes the measure of persistence of volatility shocks is also given by the sum of the coefficients $\alpha$ and $\beta$. The high degree of persistence in empirical applications could therefore be due to the existence of a $\operatorname{GARCH}(1,1)$ process with high degree of kurtosis, which forces the sum of GARCH coefficients to be close to one.

Two factors have been pointed out to explain the high persistence estimated in GARCH process: the existence of outliers (Carnero et al., 2001; Hotta and Tsay, 1998; Verhoeven and McAleer, 2000) or the existence of level shifts in the variance process (Lamoreaux and Lastrapes, 1993).

For our purpose, the main factor is the existence of important price spikes in electricity markets (outliers) that could affect the parameter estimates of the volatility process. Observe for example, that the estimated value of the parameter $\alpha$ in Model 2 is always larger than that estimated value in Model 4 that allows for both $\operatorname{GARCH}(1,1)$ and jumps. This difference is even bigger for the cases of Argentina, Australia and PJM. Notice that the parameter $\alpha$ may increase due to the existence of occasional periods of high volatility but with low persistence. As we may see from Figures 1 to 6 , the huge increases in prices that exist during a short period of time (few days) clearly appear in the electricity price series of Argentina, Australia and PJM markets.

Another alternative specification, when moving beyond the simple constant variance model, is to allow for jumps, see Model 3 of Appendix B. Observe that in the six electricity markets, there is an improvement in goodness of fit when moving from Model 1 to Model 3. The parameters corresponding to the jump process $\left(\lambda, \mu_{\mathrm{J}}, \sigma_{\mathrm{J}}\right)$ are all statistically significant in all the markets. Only in the New Zealand market, $\mu_{\mathrm{J}}$ is not statistically different from zero, which means that the AVERAGE jump size is nearly zero. However, this does not imply jump process is not important to understand behavior of electricity prices. We can check the 
improvement when modeling jumps with either the value of the log-likelihood function (Schwarz Information Criterion) or by a Likelihood Ratio tests which are provided in Table B.7 of Appendix B.

Furthermore, we also have estimated Model 3b, in order to take into account for probability of observing a jump not to be constant through time. In particular in Model $3 b, \lambda$ is a function of seasonal dummies (one per season), see Appendix B for the particular parameterization used.

Our results confirm our intuition that the probability of observing jumps is not constant. From this result we should expect to have a time varying jump risk premium in futures prices. An interesting topic for future research is to analyze which of the following variables: demand, hydro reservoir, etc. should explicitly be included in the model in order to identify the fundamentals behind the observed jumps in electricity prices. Going one step further, we could also study how futures markets prices jump risk.

By doing pair-wise comparisons of log-likelihoods between nested models based on Likelihood Ratio Test, see Table 7 in Appendix B, we conclude GARCH-Poisson-Gaussian model outperforms: the constant volatility model (Model 1), the GARCH model (Model 2), the pure jump model (Model 3 and 3b) in all of the electricity markets but Spain (Spain is different!). (The oligopoly modeling approach of Fabra and Toro (2001) of the Spanish electricity market, is informative about the particular microstructure characteristic of the market which together with the particular rules for compensating the generators for the costs incurred in the transition to competition (CTC), make the Spanish market to evolve differently).

We therefore conclude that both sources of uncertainty, stochastic volatility and discrete jumps, are useful in explaining the volatility clustering, the skewness and the excess kurtosis observed in most of the electricity markets.

We check the interaction of these two sources of volatility (GARCH behavior and jumps) by analyzing the results of Model 4. In the case of NordPool, Australia and New Zealand, model 4 provides the best fit among all models. In all the markets except Spain we may see that the GARCH process is stationary in Model 4 and that the estimated probability of observing a jump, i.e. the estimated $\lambda$, is smaller than the reported in Model 3. We interpret this result as a support of the idea of take into account both sources of volatility. Therefore jumps and GARCH are complementary rather than substitute factors in a model for electricity prices.

Finally, Model $4 \mathrm{~b}$ allows for time dependency in the intensity of the Poisson process. In the case of Argentina model $4 \mathrm{~b}$ best fits data (under the Schwartz Criterion, SC). In the case of Argentina (see also PJM), there is a clear seasonal pattern in jump behavior, with a higher probability of observing a jump in June, July or August. In this case the effects of jump and volatility appear in a clear way. We may observe the sharp decrease in the estimated value of $\alpha$ when allowing for jumps (see also the results for Victoria and PJM). Also note that when moving from Model 3 to Model 4, the intensity of the Poisson process $(\lambda)$ decreases (because part of the movements of the price series are captured by the GARCH process), although the estimated mean jump decrease is not statistically significant.

The Spanish market deserves a special comment. The results for this market point out as the best model, Model 2. The estimated GARCH $(1,1)$ process in model 2 is stationary. When we include jumps and estimate Model 4 we see that either the jump process is not statistically significant (in the case of seasonality with sinusoidal function) or we obtain an estimate of $\omega$ not statistically significant in Model 4 (with monthly 
dummies). We believe that one of the main reasons for getting this unique behavior of the Spanish market are the institutional framework. Mainly, the way stranded costs (or CTC) are treated in the Spanish deregulation process creates conflictive incentives on the few players that are in the Spanish market, see Federico and Whitmore (1999) and Fabra and Toro (2001) treatment of the interaction of incentives in the Spanish market and its consequences on energy price risk. Basically, the amount of stranded costs to be paid to generators depends negatively on the price observed in the pool. If prices are above a known and preestablished level, generators earn higher profits from their operations in the pool but will receive a lower amount of stranded costs. Therefore, there is a conflict of interests among power generating firms which depend on the characteristics of each firm: market share, expectations about the probability of obtaining stranded costs, etc. which affect the equilibrium price in a predictable way.

Our empirical results suggest an improvement by moving from Model 2 or Model 3 to Model 4. Moving from Model 2 to Model 4 there is not only an improvement in terms of goodness of fit but also the understanding of the behavior of electricity prices does so. On the other hand, moving from Model 3 to Model 4 the goodness of fit also improves and we observe a clear interaction between GARCH and jumps indicated by a decrease in the estimated intensity of the Poisson process. The effect of including $\operatorname{GARCH}(1,1)$ model is clear in terms of the estimated frequency of jumps, however the effect of the mean jump size is not so clear. We think there are two reasons for this ambiguous result. The first one is that since we are using average daily prices, and although there is a weekly dummy that tries to capture the lower demand on weekends, we are not capturing those holidays that are in the middle of a week, and some below average demand weekends. Probably in those days we may observe a "negative" jump, that has a mixed effect on $\mu_{J}$, because when we introduce GARCH behavior we are left with some negative and positive jumps. Clearly we are not too interested on those negative jumps since they are predictable. Probably if we work with an on-peak daily average price these problems will diminish. The other reason we have in mind is that results are not so clear in those markets where jumps are relatively less important, where GARCH behavior is more important to understand the uncertainty in that market.

More work is needed in this direction by increasing the number of analysed series, using on-peak series and/or use a different specification for $\mu_{J}$ (perhaps a time-dependent mean jump size, which is very easy to handle in our model).

Although statistically speaking there is no huge improvement when we allow for time-dependent intensity this is an appealing possibility if we want to understand other aspects of these markets. For instance, the fact that there are time-dependent intensities could affect the behavior of risk premium, and the term structure of forward curves. Those questions are left for future research.

\section{UNIT ROOT TESTS}

Traditional unit root tests, like Dickey-Fuller (1979) are powerful against most mean-reverting alternatives if the errors are homoskedastic and there is no jumps in the data (stationarity). Pindyck (1999) deals with the issue of unit roots test in the context of energy commodities (oil, gas, coal). In part, because 
Pindyck (1999) focus on the long-run evolution of energy prices he does not take into account the possibility of jumps or non-constant volatility in his unit root tests.

However, as we have seen in the previous section, those stationarity conditions are not satisfied by equilibrium electricity prices. We propose to generalize recent powerful methods proposed in the econometric literature that independently take into account the effects of heterocedasticity-GARCH $(1,1)$ errors, see Boswijk (2000), and outliers when testing for the presence of unit roots, see Arranz, Escribano and Marmol (2000).

From our empirical analysis we conclude that the most appropiate model for equilibrium electricity prices $\left(P_{t}\right)$ is a flexible model (Model $4 \mathrm{~b}$ of Appendix B) with deterministic seasonality, autoregressive $(\mathrm{AR}(1))$ and $\operatorname{GARCH}(1,1)$ errors and with jumps with time dependent intensity of the Poisson process. That is,

$$
P_{t}=f(t)+X_{t}
$$

where $f(t)$ is defined in equation (8) and the stochastic term $X_{t}$ is generated by an $\mathrm{AR}(1)$ process with heterokedastic errors and additive outliers.

$$
X_{t}=\phi \cdot X_{t-1}+\eta_{t}
$$

where the errors $\eta_{\mathrm{t}}$ follows a $\operatorname{GARCH}(1,1)$ process with jumps of time dependent intensities generated by a Poisson distribution. That is,

$$
\begin{aligned}
& \eta_{t}=\left\{\begin{array}{c}
h_{t}^{1 / 2} \varepsilon_{1 t} ; \quad \text { with prob. } 1-\lambda_{t} \\
h_{t}^{1 / 2} \varepsilon_{1 t}+\mu_{J}+\sigma_{J} \cdot \varepsilon_{2 t} ; \quad \text { with prob. } \lambda_{t}
\end{array}\right. \\
& h_{t}=\omega+\alpha \cdot \varepsilon_{t-1}+\beta \cdot h_{t-1} \\
& \lambda_{t}=L 1 \cdot \text { winter }_{t}+L 2 \cdot \text { fall }_{t}+L 3 \cdot \text { spring }_{t}+L 4 \cdot \text { summer }_{t}
\end{aligned}
$$

where $\varepsilon_{1 t}, \varepsilon_{2 t}$ and $\varepsilon_{t} \sim$ i.i.d. $N(0,1)$ and mutually independent. The objective now is to test the null hypothesis of a unit root, $\mathrm{H}_{0}: \phi=1$, against the mean reverting alternative hypothesis, $\mathrm{H}_{1}: \phi<1$.

\subsection{Standard Unit Root Test, Dickey and Fuller(1979)}

The most common procedure for testing the unit root hypothesis is to use Dickey-Fuller (DF) or Augmented Dickey-Fuller (ADF) type of tests in the context of independent, Gaussian and homokedastic errors, term $\varepsilon_{t}$ on equation (17). As a benchmark, we report results of ADF-test for the unit root null hypothesis, $\mathrm{H}_{0}:(\phi-1)=0$, against the alternative of mean reverting, $\mathrm{H}_{1}:(\phi-1)<0$. The ADF-test is based on the t-ratio of $(\phi-1)$ in the following regression equation, 


$$
\Delta X_{t}=c+(\phi-1) \cdot X_{t-1}+\sum_{j=1}^{r} \phi_{j} \Delta X_{t-j}+\varepsilon_{t}
$$

The maximum order of the lags ( $\mathrm{r}$ ) differs in each of the individual market price series $\left(\mathrm{X}_{\mathrm{t}}\right)$ and it is empirically determined in order to warranty that the residuals (estimates of $\varepsilon_{\mathrm{t}}$ ) have no serial correlation. Table 6.1 includes the empirical results of the ADF-test for the five electricity markets $(\mathrm{NP}=$ NordPool, $\mathrm{ARG}=$ Argentina, $\mathrm{VIC}=$ Victoria, $\mathrm{NZ}=$ New Zealand and $\mathrm{SP}=$ Spain $)$ with the approximate $5 \%$ critical value.

Table 6.1.: Unit Root Tests (ADF)

\begin{tabular}{|l|c|c|}
\hline Series & ADF Test Statistic & 5\% Critical Value (McKinnon Critical Values) \\
\hline NP & $-2,922$ & $-2,863$ \\
\hline ARG & $-6,376$ & $-2,863$ \\
\hline VIC & $-6,947$ & $-2,863$ \\
\hline NZ & $-6,031$ & $-2,864$ \\
\hline SP & $-4,686$ & $-2,865$ \\
\hline PJM & $-4,077$ & $-2,864$ \\
\hline
\end{tabular}

Those results of Table 6.1, show that the unit root hypothesis is always rejected, in favor of mean reverting alternative, at a 5\% significance level. The lowest rejection occurs in the NordPool, as expected from the empirical results mentioned in the previous section. However, in the application of unit root test to electricity prices one has to face two additional problems that in principle creates doubts on the credibility of those empirical results. First, the presence of volatility (GARCH) and second, the existence of outliers (jumps) in the data. Most unit root testing procedures are sensitive to the occurrence of anomalous events (outliers, etc.) and also to the presence of heteroskedasticity, specially with near-integrated volatility.

In what follows, we present the empirical results of addressing each of these issues independently and we also suggest a new sequential unit root testing procedure when both problems appear in the price series.

\subsection{Unit Root Tests with GARCH(1,1) errors: Boswijk (2001).}

In cases where the error term follows a GARCH process, estimation and testing for a unit root involves intrinsic problems, Pantula (1989). Peters and Veloce (1988) and Kim and Schmidt (1993) provided simulation results to show that Dickey-Fuller tests based on LS estimators are often sensitive and, when $\alpha+$ $\beta<1$ but is close to 1 , the problem can be very serious. Ling et al. (2001) show by simulation analysis that tests based on ML estimators perform better than tests based on LS estimators (Dickey-Fuller). Boswijk (2000) considers tests for a unit root when the innovations follow a near-integrated GARCH process. As we have seen in agreement with Duffie et al. (1998) near-integrated GARCH processes are common in electricity price series. Typical unit root test rely on the constant volatility assumption. If the series has heterocedasticity, Least Squares estimates are not efficient, and the test might not be able to detect the (low) mean-reversion. The results in Boswijk (2000) point out an increase in power in unit root test (LR type of test) when the test takes into account the possibility of $\operatorname{GARCH}(1,1)$ behavior. The increase in power is 
higher when $\alpha+\beta \approx 1$, specially if $\alpha$ is high (large short-run variation in the volatility), as it is usually the case with electricity price series.

We report the results for the unit root test proposed by Boswijk (2001). The test is a Likelihood Ratio type of test based on the following specification:

$$
\begin{aligned}
& \Delta X_{t}=(\phi-1)\left(X_{t-1}-\mu\right)+\varepsilon_{t} \cdot h_{t}^{1 / 2} \\
& h_{t}=\omega+\alpha \cdot \varepsilon_{t-1}^{2}+\beta \cdot h_{t-1} \\
& \eta_{t} \sim \text { i.i.d.N }(0,1)
\end{aligned}
$$

The parameter $(\phi-1)$ describes the degree of mean-reversion. The null hypothesis is the unit root hypothesis, $H_{0}:(\phi-1)=0$, which is tested against the mean reversion alternative, $\mathrm{H}_{1}:(\phi-1)<0$.

The likelihood ratio statistic for the null hypothesis is

$$
L R=-2 \cdot\left(l\left(\boldsymbol{\theta}_{R}\right)-l\left(\boldsymbol{\theta}_{U}\right)\right)
$$

where $\theta_{R}$ and $\theta_{U}$ are the restricted and unrestricted maximum likelihood estimators respectively. The limiting distribution of LR under the null hypothesis depends on a nuisance parameter. The nuisance parameter can be expressed (and therefore estimated) as a function of the GARCH parameters. For details on the limiting distribution and the calculation of the p-values, see Boswijk, (2001) and Boswijk and Doornik, (1999).

Table 6.2.: Unit Root Tests (Boswijk, 2001)

\begin{tabular}{|c|c|c|}
\hline Series & LR & p-value \\
\hline NP & 20,07 & 0,0033 \\
\hline ARG & 192,4 & 0,00 \\
\hline VIC & 65,71 & 0,00 \\
\hline NZ & 135,08 & 0,00 \\
\hline SP & 168,76 & 0,00 \\
\hline PJM & 320,4 & 0,00 \\
\hline
\end{tabular}

This test statistic clearly rejects the unit root hypothesis in all markets.

\section{3. Unit Root Test in the Presence of Outliers: Arranz, Escribano and Marmol (2000).}

The presence of additive transitory outliers in the series biases unit root inference towards rejection of the unit root hypothesis, see for instance Franses and Haldrup (1994). We use a procedure recently proposed in the literature in order to deal with this issue. Arranz et al. (2000) have proposed to use a nonlinear filter (median filter) before we test for unit roots when the series has additive outliers. The methodology proposed by Arranz et al. (2000) consists on applying Dickey-Fuller tests on the filtered series. We have selected this procedure based on three arguments: this procedure is robust to the presence of additive outliers, it improves the performance of traditional unit root tests and it much easier to apply than other test based on robust estimation procedures, see for example Lucas (1995 a, b), Vogelsang (1999) and $\mathrm{Ng}$ and Perron (1998) . 
We report the results obtained for the unit root test proposed by Arranz et al., (2000). The test consists on 2step: First filter the data $\left(\mathrm{X}_{\mathrm{t}}\right)$ with the "median filter",

$$
X_{t}^{*}=\operatorname{median}\left(X_{t-k}, \ldots, X_{t}, \ldots X_{t+k}\right) .
$$

That is, $X_{t}^{*}$ is the filtered values of $X_{t}$ where the value of $\mathrm{k}$ is set $k=2$, following the simulation results of Arranz, et al. (2000). In the second step, apply an ADF-test based on the regression equation,

$$
\Delta X_{t}^{*}=c+(\phi-1) \cdot X_{t-1}^{*}+\sum_{j=1}^{r} \phi_{j} \Delta X_{t-j}^{*}+\varepsilon_{t}
$$

Table 6. 3. Unit Root Test, Arranz et al., (2000)

\begin{tabular}{|c|c|c|}
\hline Series & ADF Test Statistic & 5\% Critical Value (McKinnon critical values) \\
\hline NP & $-2,937$ & $-2,863$ \\
\hline ARG & $-6,696$ & $-2,863$ \\
\hline VIC & $-5,246$ & $-2,863$ \\
\hline NZ & $-6,543$ & $-2,864$ \\
\hline SP & $-4,883$ & $-2,865$ \\
\hline PJM & $-6,788$ & $-2,864$ \\
\hline
\end{tabular}

Table 6.3 reports the ADF results with the corresponding critical value (at 5\%). Once again, we reject with a $95 \%$ confidence the unit root hypothesis against the mean reversion alternative for all the electricity markets.

\subsection{Unit Root Testing Procedures in the Presence of Outliers and GARCH(1,1) Errors: a Bootstrap}

\section{Approach.}

One of the main limitations of those recent unit roots tests statistics is the fact that they could deal with either the presence of GARCH or alternatively with the presence of jumps but they cannot cope simultaneously with both. Our goal now is to provide a new testing strategy that is able to cope with the simultaneous presence of GARCH and jumps in the context of unit root testing. 
We propose to implement this testing strategy in two step:

First, apply the median filter of Arranz et al. (2000) to the original series $\left(\mathrm{P}_{\mathrm{t}}\right)$ without deterministic seasonal components on it, $\left(\mathrm{X}_{\mathrm{t}}\right)$ in equation (12), and generate $\mathrm{X}_{\mathrm{t}}^{*}$.

Second, apply the test proposed by Boswijk (2000) to the transformed series $\mathrm{X}_{\mathrm{t}}^{*}$.

Since we do not know the limiting distribution, nor the small sample distribution of Boswijk's LR test when it is applied to $\mathrm{X}_{\mathrm{t}}^{*}$, we suggest to implement the LR-test by bootstrap (re-sampling) techniques.

In particular, we are allowing the equilibrium price series to have non-constant volatility $(\operatorname{GARCH}(1,1))$ and outliers (additive), see equations (12)-(16). In order to simultaneously take into account these two features, we suggest to sequentially apply both Arranz et al. (2000) and Boswijk (2001) procedures. The idea basically is to use a powerful test for unit root in the presence of $\operatorname{GARCH}(1,1)$ errors, taking also into account the existence of outliers and seasonality. In order to do so, we apply the median filter to the "deseasonalized" series (preliminary steps). Once we have done those corrections we apply Boswijk's unit root test combined with bootstrap techniques in order to obtain valid the critical values.

Let $\mathrm{X}_{\mathrm{t}}^{*}$ be the equilibrium price series without seasonality and filtered with the median filter, equation (14) with $\mathrm{k}=2$. We are interested in testing the null of unit root in the following model:

$$
\begin{aligned}
& \Delta X_{t}^{*}=c+(\phi-1) \cdot X_{t-1}^{*}+\varepsilon_{t} \cdot h_{t}^{1 / 2} \\
& h_{t}=\omega+\alpha \cdot \varepsilon_{t-1}^{2}+\beta \cdot h_{t-1}
\end{aligned}
$$

That is we want to test the null hypothesis $H_{0}:(\phi-1)=0$ against $H_{1}:(\phi-1)<0$ with the Boswijk's LR statistic. Let $\{\hat{c}, \hat{\omega}, \hat{\alpha}, \hat{\beta}\}$ be the QML parameter estimates of model (16) under $\mathrm{H}_{b}$ and let $\varepsilon_{t}^{*}$ be the bootstrap residuals from the QML residuals. Next, in order to generate bootstrap samples we have used the following scheme under the null hypothesis $\left(\mathrm{H}_{0}\right)$ :

$$
\begin{aligned}
& \Delta Z_{t}^{*}=\hat{c}+\varepsilon_{t}^{*} \cdot h_{t}^{*} \\
& h_{t}^{*}=\hat{\omega}+\hat{\alpha} \cdot \varepsilon_{t-1}^{*}+\hat{\beta} \cdot h_{t-1}^{*}
\end{aligned}
$$

We have done $\mathrm{NB}=1000$ bootstrap re-samples. For each sample we have estimated the model under the null and under the alternative and we have calculated their corresponding LR statistic. The bootstrap critical value is obtained by looking at the 5\% lower tail of the empirical distribution of these Likelihood Ratios. In summary, the new unit root sequential testing procedure is:

Step 1: Eliminate seasonality. Define $\mathrm{X}_{\mathrm{t}}=\mathrm{P}_{\mathrm{t}}-f(t)$, where $\mathrm{P}_{\mathrm{t}}$ is the equilibrium electricity price series and $f(t)$ is the seasonal function defined in equation (8) using the parameter values estimated from Model 4 (Tables B.1 to B.5 of Appendix B).

Step 2: Apply the median filter of equation (14) to $X_{t .}$. That is generate $X_{t}^{*}=\operatorname{median}\left(X_{t-k}, \ldots, X_{t}, \ldots X_{t+k}\right)$ for $\mathrm{k}=2$.

Step 3: Estimate the model (21) by QML under the null $\left(H_{0}:(\phi-1)=0\right)$ and under the alternative $\left(H_{1}:(\phi-1)<0\right)$. Calculate and store the LR statistic in each case. Call this LR statistic $\mathrm{LR}_{\mathrm{Z}}$. 
Step 4: The QML residuals obtained under the null are used to generate NB bootstrap samples with the previous scheme (22). We have set NB $=1000$.

Step 5: From the bootstrap samples $\left(Z_{t}^{*}\right)$ we obtain bootstrap QML estimates and the corresponding log-likelihood values, under the null and under the alternative, and the Likelihood Ratio $\left(\mathrm{LR}_{\mathrm{Z}}\right)$ is recorded.

Step 6: The hypothesis $H_{0}:(\phi-1)=0$ is rejected if $\mathrm{LR}_{\mathrm{Z}}$ is bigger than the corresponding bootstrap critical value, obtained by looking at the $5 \%$ lower tail of the empirical distribution.

Table 6.4 Results for Likelihood Ratio, critical value and p-value

\begin{tabular}{|l|c|c|l|}
\hline Series & Likelihood Ratio $\left(\mathrm{LR}_{\mathrm{Z}}\right)$ & 5\% bootstrap critical value & p-value \\
\hline NP & 7,15 & 6,99 & 0,046 \\
\hline ARG & 150,82 & 10,58 & 0,000 \\
\hline VIC & 112,95 & 7,44 & 0,000 \\
\hline NZ & 35,98 & 10,46 & 0,003 \\
\hline SP & 28,96 & 10,64 & 0,004 \\
\hline PJM & 248,25 & 25,41 & 0,000 \\
\hline
\end{tabular}

The results of the proposed unit root tests, see Table 6.4, allow us to reject with a 95\% confidence the null hypothesis of unit root in all the series. Furthermore, from the estimation results of the previous section we know that the NordPool estimate of the autoregressive parameter, $(\operatorname{AR}(1))$, is the largest and it is near a unit root. From the sequential testing procedure that we have proposed we observe that in the NordPool the unit root hypothesis can be rejected at $5 \%$ and that the p-value of the NordPool ${ }^{3}$ is highest. Since the bwest power in unit root test occurs when the roots are near unity, we should not be surprised by this result.

Our purpose in the near future is to do risk management in electricity markets and for that we will consider that prices from the NordPool are slowly mean reverting. For other modeling purposes like forecasting, cointegration, etc., the mistake one can make by imposing that there is a unit root in the NordPool when in fact is slowly mean reverting should not be important and it could even be of some help, see for instance the cointegration approach of De Vany and Walls(1999).

\section{CONCLUSIONS AND FURTHER RESEARCH}

Deregulation in electricity sector has among other things introduced price uncertainty. The main concern of this paper is the source of equilibrium price uncertainty generated in each "pool" as a result of the evolution of the intersections of demand and supply of electricity. We have shown the high degree of volatility and the existence of price spikes (jumps) in several international markets. We have presented a general model for electricity prices in deregulated markets that jointly takes into account those factors and provides both empirical evidence and economic intuition for the presence of these factors, and the interaction among them.

\footnotetext{
${ }^{3}$ For the NordPool case we also have done the bootstrap analysis with 2000 bootstrap replications. In this case, the critical value was 6,67 and the p-value was 0,039 .
} 
The main factors are: seasonality, mean-reversion, conditional heterokedasticity and jumps. We have shown that our model is flexible enough to incorporate the main characteristics of equilibrium electricity prices in a set of different markets. We have shown the adequacy of our model even for series with different degrees of seasonality, different degree of persistence of shocks in the equation of the mean, different jump intensities (different levels of kurtosis) and different markets structures (different echnology mix in the power generators offering electricity in each market).

We also provide a detailed analysis of mean-reversion in electricity prices. We did a comprehensive set of unit root tests that take into account the effect of heterokedasticity and outliers. The new unit root testing strategy proposed in this paper allow us to conclude that in five markets analyzed using daily data; Argentina, Australia (Victoria), New Zealand (Hayward), Nordpool, PJM and Spain, equilibrium electricity prices are mean-reverting. As expected, the lowest degree of mean-reversion is observed in the NordPool, but even in this case the mean reverting degree increases when we simultaneously allow for jumps and GARCH behavior. Although the GARCH(1,1) behavior is an important factor in general, the inclusion of both GARCH and jumps are needed (except for the Spanish market) to get convincing results.

Our empirical methodology is flexible enough to model some other plausible characteristic elements of equilibrium electricty prices. For example, given the seasonality observed in the electricity demand and given the convexity of the electricity supply function, seasonal volatility could also be an interesting aspect to consider when modeling equilibrium electricity prices. In our approach we tried to capture this behavior by means of a time-dependent intensity process. However, other alternatives are available like the introduction of periodic specifications of the GARCH(1,1) process (Bollerslev and Ghysels 1996). We could also include some kind of asymmetric GARCH behavior, see Knittel and Roberts (2001). The idea is that the convexity of the supply stack implies some asymmetric behavior on the volatility of electricity prices contingent on the sign of the shock. For example, Knittel and Roberts $(2001)$ estimated an EGARCH $(1,1)$ model (without jumps) to California electricity prices finding an "inverse leverage effect". Therefore, a plausible extension could be to consider and EGARCH with jumps, in order to capture the volatility effect on the jump estimates. Another interesting extension would be to introduce some explanatory variables in the jump process like, demand or capacity of the system, which will affect the probability of observing a jump $(\lambda)$ or the mean jump size $\left(\mu_{\mathrm{J}}\right)$.

However, our next line of research in the near future is to use our estimated models in the analysis and quantification of risk management. Given that we are jointly taking into account two sources of uncertainty, jumps and stochastic volatility, and since we found some predictable component in the estimated jumps, we could compare the Value at Risk (VaR) estimates from our specification to those obtained with more established methods. In particular, we could compare the VaR estimates "a la Riskmetrics", that only take into account GARCH uncertainty, with our modeling procedure that also allows for jumps of time dependent intensity. Furthermore on the valuation side, since we are able to quantify the relative role of jumps and stochastic volatility, we could search for evidence on the type of risk premiums that are relevant for pricing of derivatives in electricity markets. Those questions are out of the scope of this paper and are left for future research. 


\section{APPENDIX A}

This table presents descriptive statistics for a set of daily average electricity spot prices for different countries. Summary statistics are reported for the price level, units are expressed in local currency.

Series analyzed and samples:

NordPool (NP): January 1, 1993 - November 30, 1999

Argentina (Arg): January 1, 1995 - September 30, 2000

Australia, Victoria (Vic): July 1, 1994 - December 12, 1999

New Zealand, Hayward (NZ): October 1, 1996 - August 31, 2000

Spain (SP): January 1, 1998 - December 31, 2000

U.S., PJM (PJM): April 1, 1998 - December 31, 2001

Table 1. Descriptive statistics.

\begin{tabular}{|c|c|c|c|c|c|c|c|c|}
\hline Series & N. Obs. & Mean & Med. & Min. & Max. & Std.Dev & Skew. & Kurt. \\
\hline NP & 2525 & 142,59 & 132,12 & 14,81 & 423,38 & 66,70 & 0,75 & 3,51 \\
\hline ARG & 2100 & 18,79 & 17,46 & 8,03 & 111,44 & 6,39 & 6,39 & 35,65 \\
\hline VIC & 1991 & 25,55 & 20,70 & 1,46 & 441,28 & 22,56 & 6,57 & 87,26 \\
\hline NZ & 1431 & 37,12 & 38,40 & 0,58 & 115,00 & 14,32 & 0,04 & 3,63 \\
\hline SP & 1096 & 4,52 & 4,42 & 1,62 & 8,54 & 1,04 & 0,91 & 4,48 \\
\hline PJM & 1370 & 27,92 & 22,57 & 8,19 & 397,34 & 25,58 & 7,60 & 76,44 \\
\hline
\end{tabular}


Figure 1a: NordPool. Daily Average Price.

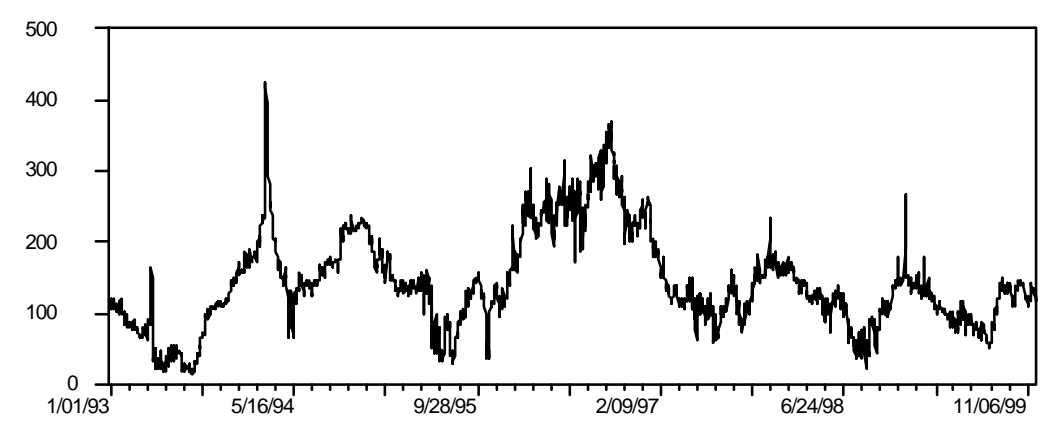

Figure 1b: NordPool. Empirical Distribution (Kernel Density, Epanechnikov, h = 22,679)

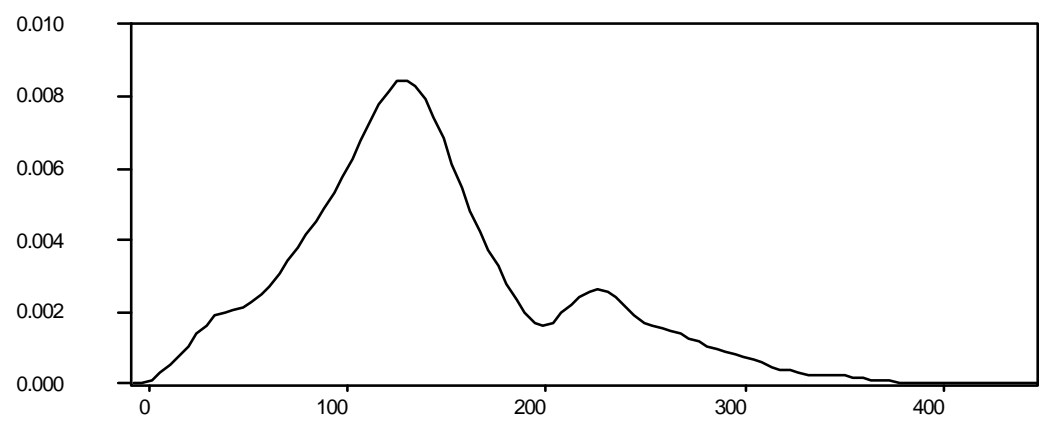

Figure 2a: Argentina. Daily Average Price.

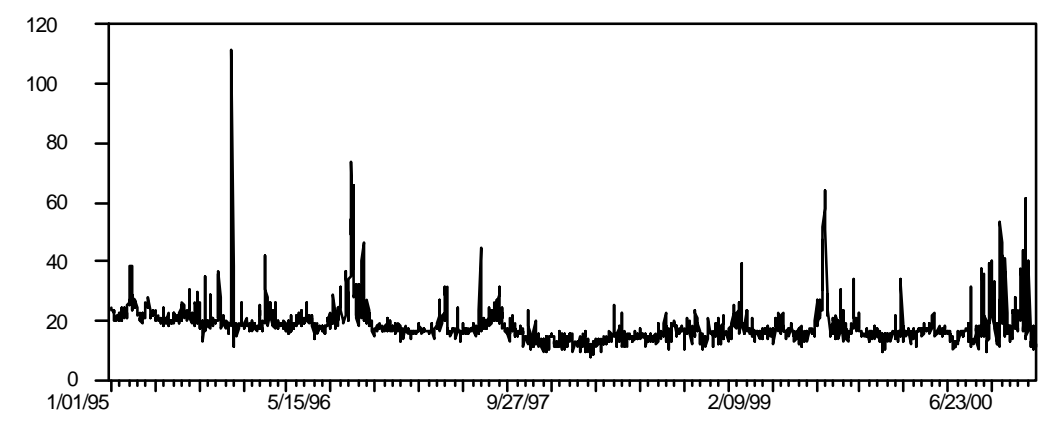

Figure 2b: Argentina. Empirical Distribution (Kernel Density, Epanechnikov, h = 1,5116)

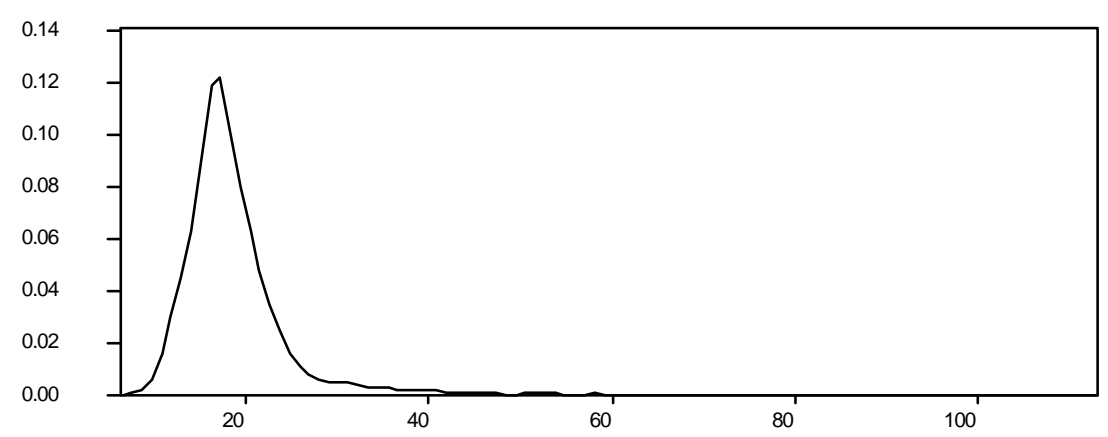


Figure 3a: Australia. Daily Average Price.

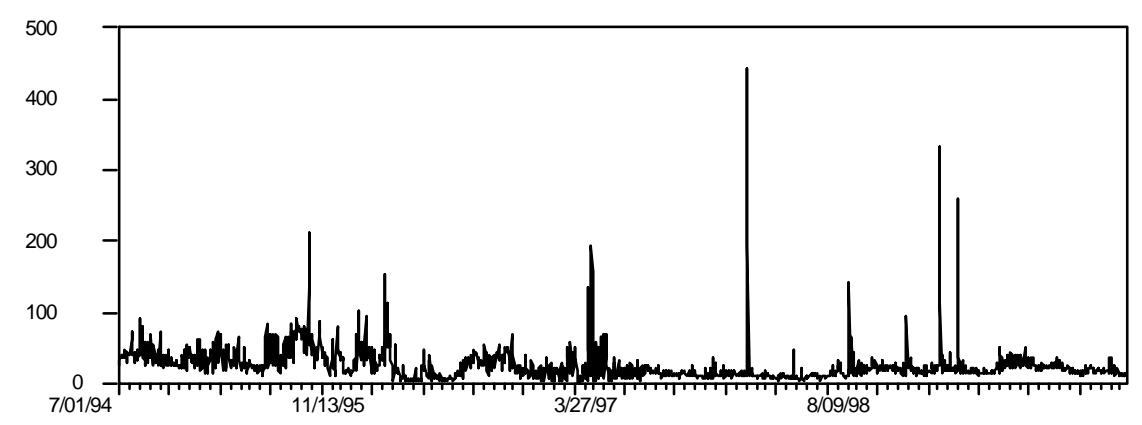

Figure 3b: Australia. Empirical Distribution. (Kernel Density, Epanechnikov, h = 5,9686)

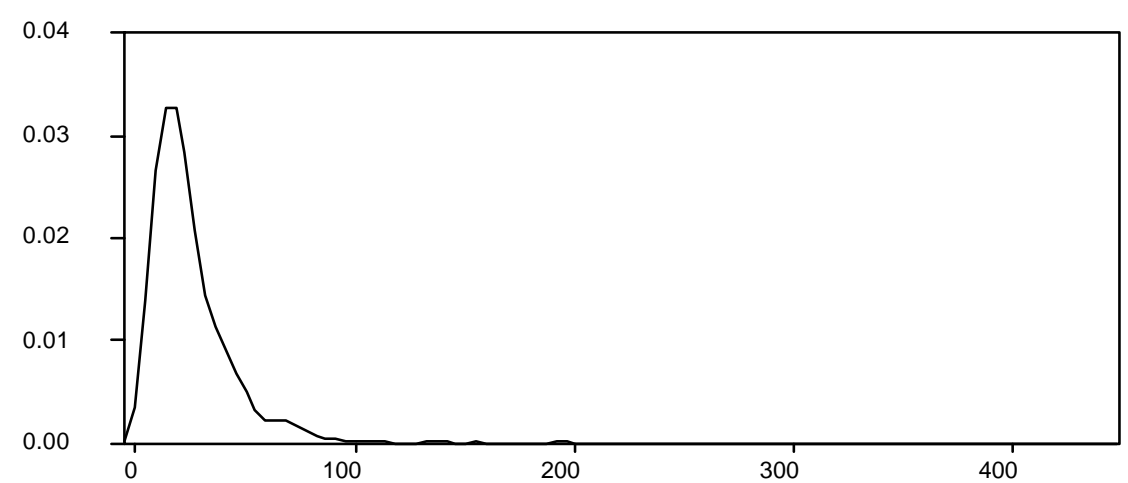

Figure 4a: New Zealand. Daily Average Price.

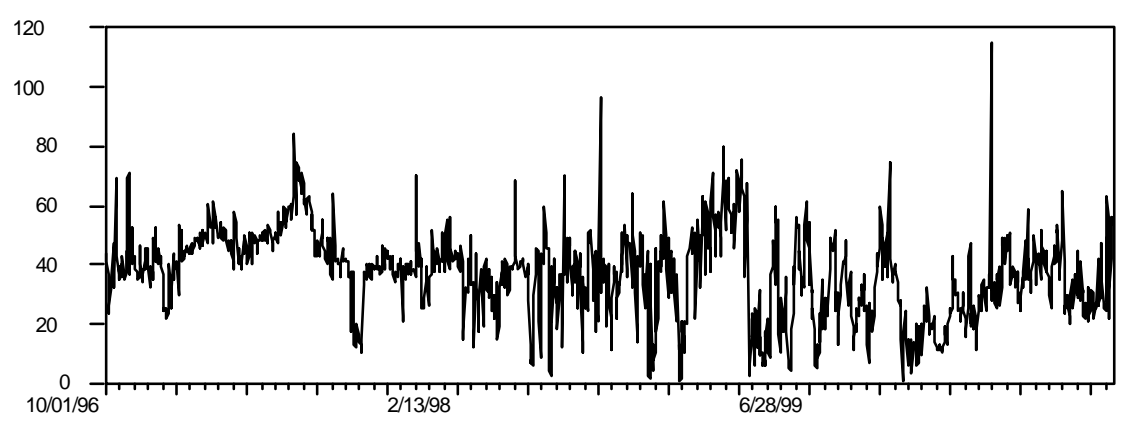

Figure 4b: New Zealand. Empirical Distribution. (Kernel Density, Epanechnikov, h = 6,2931)

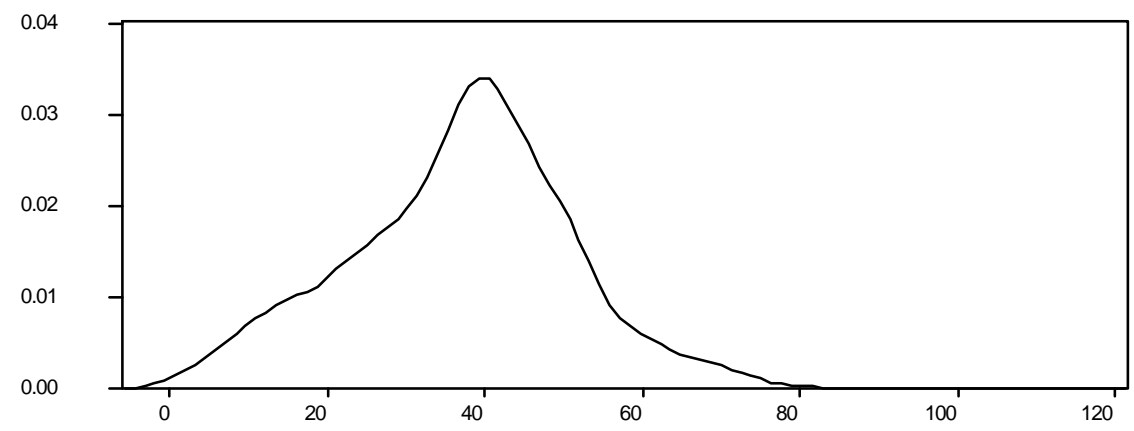


Figure 5a: Spain. Daily Average Price.

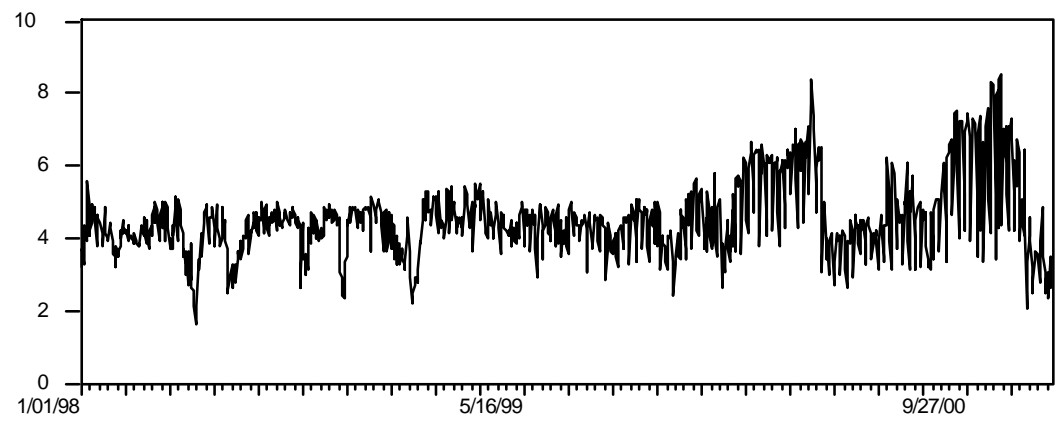

Figure 5b: Spain. Empirical Distribution. (Kernel Density, Epanechnikov, h = 0,3521)

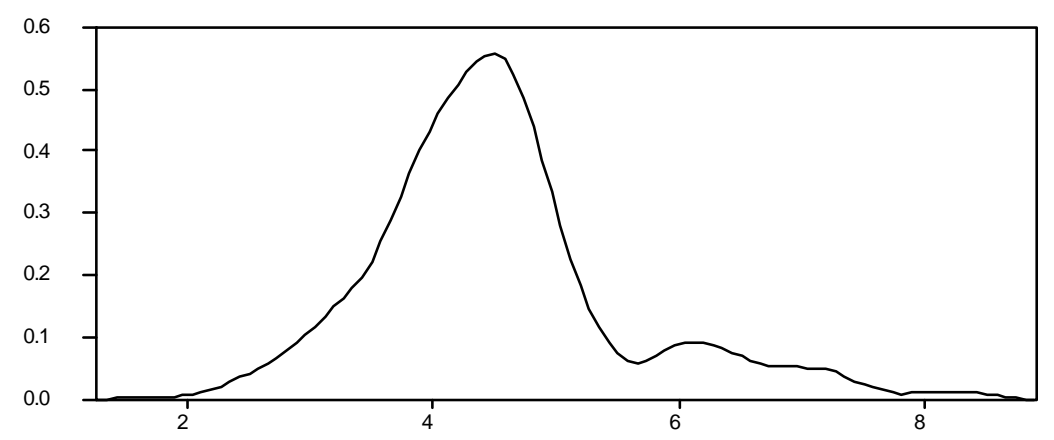

Figure 6a: PJM. Daily Average Price.

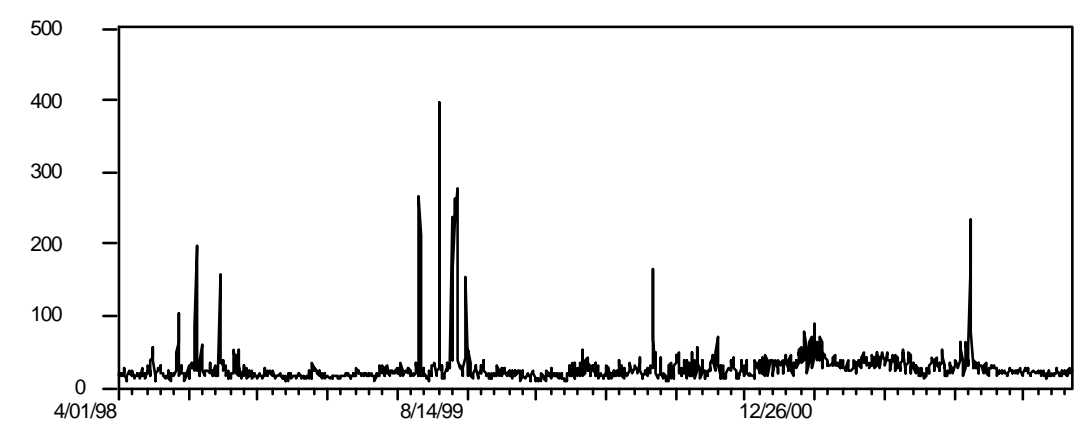

Figure 6b: PJM. Empirical Distribution. (Kernel Density, Epanechnikov, h = 4,3946 )

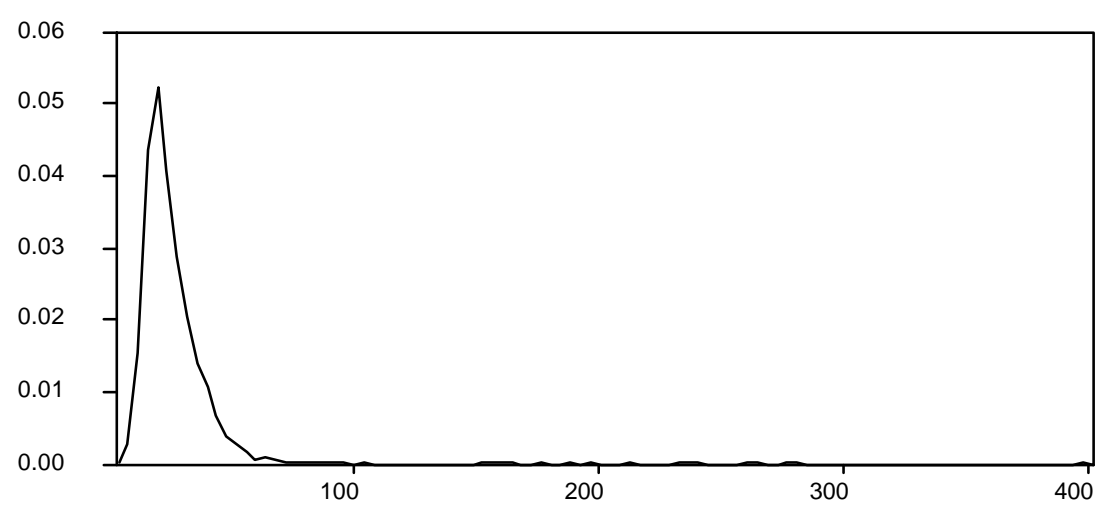




\section{APPENDIX B: MODELS AND EMPIRICAL RESULTS}

Model 1: Autoregressive (AR(1)), constant volatility model with no jumps (pure diffusion model).

$$
\begin{gathered}
P_{t}=f(t)+X_{t} \\
X_{t}=\phi X_{t-l}+\sigma \varepsilon_{1 t} \\
\varepsilon_{1 t} \sim \text { i.i.d. } N(0,1)
\end{gathered}
$$

Model 2: Autoregressive (AR(1)), GARCH(1,1) model with no jumps.

$$
\begin{gathered}
P_{t}=f(t)+X_{t} \\
X_{t}=\phi X_{t-1}+h^{0.5} \varepsilon_{t-1} \\
h_{t}=\omega+\alpha \varepsilon_{t-1}+\beta h_{t-1} \\
\varepsilon_{l t} \sim \text { i.i.d. } N(0,1)
\end{gathered}
$$

Model 3: Autoregressive (AR(1)), pure jump model.

$$
X_{t}=\left\{\begin{array}{c}
P_{t}=f(t)+X_{t} \\
\phi X_{t-1}+\sigma \cdot \varepsilon_{l t} ; \text { prob. } 1-\lambda \\
\phi X_{t-1}+\sigma \cdot \varepsilon_{1 t}+\mu_{J}+\sigma_{J} \cdot \varepsilon_{2 t} \text {; prob. } \lambda \\
\varepsilon_{1 t}, \varepsilon_{2 t} \sim \text { i.i.d. } N(0,1)
\end{array}\right.
$$

Model 3b: Autoregressive (AR(1)), pure jump model, intensity of the Poisson process time dependent.

$$
\begin{gathered}
P_{t}=f(t)+X_{t} \\
X_{t}=\left\{\begin{array}{c}
\phi X_{t-1}+\sigma \cdot \varepsilon_{l t} ; \text { prob. } 1-\lambda_{t} \\
\lambda_{t}=L 1 \cdot \text { winter }_{t}+L 2 \cdot \text { fall }_{t}+L 3 \cdot \text { spring }_{t}+L A \cdot \text { summer }_{t} \\
\varepsilon_{1 t}, \varepsilon_{2 t} \sim \text { i.i.d. } N(0,1)
\end{array}\right.
\end{gathered}
$$

Model 4: AR(1), GARCH(1,1) model with jumps, intensity of Poisson process constant.

$$
X_{t}=\left\{\begin{array}{c}
P_{t}=f(t)+X_{t} \\
\phi \cdot X_{t-1}+h_{t}^{1 / 2} \varepsilon_{l t} ; \text { prob. } 1-\lambda \\
\phi \cdot X_{t-1}+h_{t}^{1 / 2} \varepsilon_{l t}+\mu_{J}+\sigma_{J} \cdot \varepsilon_{2 t} ; \text { prob. } \lambda \\
h_{t}=\omega+\alpha \cdot \varepsilon_{t-1}+\beta \cdot h_{t-1} \\
\varepsilon_{1 t}, \varepsilon_{2 t} \sim \text { i.i.d. } N(0,1) .
\end{array}\right.
$$


Model 4b: Autoregressive (AR(1)), GARCH(1,1) model with jumps, intensity of the Poisson process time dependent. This is general the model we have presented previously (equations (4) (7)).

$$
\begin{aligned}
& P_{t}=f(t)+X_{t} \\
& X_{t}=\left\{\begin{array}{c}
\phi \cdot X_{t-1}+h_{t}^{1 / 2} \varepsilon_{1 t} ; \text { prob. } 1-\lambda_{t} \\
\phi \cdot X_{t-1}+h_{t}^{1 / 2} \varepsilon_{l t}+\mu_{J}+\sigma_{J} \cdot \varepsilon_{2 t} ; \text { prob. } \lambda_{t}
\end{array}\right. \\
& h_{t}=\omega+\alpha \cdot \varepsilon_{t-l}+\beta \cdot h_{t-1} \\
& \lambda_{t}=L 1 \cdot \text { winter }_{t}+L 2 \cdot \text { fall }_{t}+L 3 \cdot \text { spring }_{t}+L A \cdot \text { summer }_{t} \\
& \varepsilon_{1 t}, \varepsilon_{2 t} \sim \text { i.i.d. } N(0,1) \text {. }
\end{aligned}
$$




\section{APPENDIX B. Estimation Results}

Table B.1: Estimation Results (NORDPOOL).

\begin{tabular}{|c|c|c|c|c|c|c|c|c|}
\hline \multirow[b]{2}{*}{ Parameter } & Model 1 & Model 2 & \multicolumn{2}{|l|}{ Model 3} & \multicolumn{2}{|l|}{ Model 3b } & \multicolumn{2}{|l|}{ Model 4} \\
\hline & Coeff. & Coeff. & Coeff. & t-stat. & Coeff. & t-stat. & Coeff. & t-stat. \\
\hline$B O$ & $137,04 \quad 63,03$ & $111,81 \quad 195,95$ & 110,14 & 65,57 & 111,75 & 66,71 & 111,73 & 181,77 \\
\hline$\phi$ & $0,93 \quad 134,69$ & $0,82 \quad 57,04$ & 0,90 & 114,22 & 0,90 & 117,43 & 0,82 & 60,61 \\
\hline DI & $7,99 \quad 4,16$ & $7,33 \quad 13,35$ & 7,56 & 5,48 & 7,51 & 5,38 & 6,41 & 11,07 \\
\hline$C l$ & $30,02 \quad 14,77$ & $38,68 \quad 58,41$ & 37,13 & 28,69 & 40,18 & 28,39 & 40,29 & 64,36 \\
\hline$C 2$ & $221,09 \quad 63,86$ & $200,13 \quad 237,81$ & 213,12 & 98,66 & 212,12 & 93,70 & 201,23 & 233,23 \\
\hline$\sigma$ & $34,26 \quad 74,35$ & & 18,50 & 24,03 & 19,22 & 28,84 & & \\
\hline$\omega$ & & $10,30 \quad 8,40$ & & & & & 6,03 & 3,67 \\
\hline$\alpha$ & & $0,41 \quad 10,58$ & & & & & 0,41 & 10,33 \\
\hline$\beta$ & & $0,59 \quad 22,98$ & & & & & 0,58 & 19,32 \\
\hline$\lambda$ & & & 0,28 & 5,65 & & & 0,04 & 0,85 \\
\hline$L 1$ & & & & & 0,14 & 4,21 & & \\
\hline$L 2$ & & & & & 0,29 & 5,67 & & \\
\hline$L 3$ & & & & & 0,26 & 5,23 & & \\
\hline$L 4$ & & & & & 0,31 & 5,14 & & \\
\hline$\mu$ & & & 50,78 & 6,43 & 53,93 & 6,94 & 15,89 & 0,91 \\
\hline$\sigma_{J}$ & & & 33,84 & 7,82 & 33,46 & 7,31 & 12,82 & 1,81 \\
\hline LL & -12505 & -11131 & -12177 & & -12165 & & -11095 & \\
\hline $\mathrm{SC}$ & 25057 & 22324,7 & 24424,5 & & 24424 & & 22278,2 & \\
\hline
\end{tabular}

Table B.2: Estimation Results (ARGENTINA ).

\begin{tabular}{|c|c|c|c|c|c|c|c|c|c|c|c|c|}
\hline \multirow[b]{2}{*}{ Parameter } & \multicolumn{2}{|l|}{ Model 1} & \multicolumn{2}{|l|}{ Model 2} & \multicolumn{2}{|l|}{ Model 3} & \multicolumn{2}{|l|}{ Model 3b } & \multicolumn{2}{|l|}{ Model 4} & \multicolumn{2}{|l|}{ Model 4b } \\
\hline & Coeff. & t-stat. & Coeff. & t-stat. & Coeff. & t-stat. & Coeff. & t-stat. & Coeff. & t-stat. & Coeff. & t-stat. \\
\hline B0 & 19,36 & 42,39 & 18,75 & 184,24 & 19,26 & 99,21 & 19,27 & 99,19 & 19,25 & \begin{tabular}{|l|}
137,14 \\
\end{tabular} & 19,22 & 136,12 \\
\hline$\phi$ & 0,61 & 96,36 & 0,56 & 33,44 & 0,58 & 53,89 & 0,58 & 53,88 & 0,55 & 23,79 & 0,55 & 23,17 \\
\hline$B 2$ & $-0,0021$ & $-8,12$ & $-0,0022$ & $-39,33$ & $-0,0028$ & $-20,41$ & $-0,0028$ & $-20,51$ & $-0,0026$ & $-24,49$ & $-0,0026$ & $-24,59$ \\
\hline DI & 2,14 & 6,64 & 1,05 & 12,32 & 1,34 & 10,62 & 1,34 & 10,74 & 1,13 & 13,19 & 1,16 & 13,35 \\
\hline$C l$ & $-2,03$ & $-6,81$ & $-1,07$ & $-15,16$ & $-1,00$ & $-8,97$ & $-0,99$ & $-9,10$ & $-0,78$ & $-8,89$ & $-0,76$ & $-8,70$ \\
\hline$C 2$ & 103,88 & 10,58 & 170,65 & 45,64 & 140,79 & 23,47 & 145,50 & 23,10 & 139,38 & 20,88 & 142,99 & 20,11 \\
\hline C3 & $-1,71$ & $-6,21$ & $-0,74$ & $-9,85$ & $-0,64$ & $-5,90$ & $-0,57$ & $-5,24$ & $-0,61$ & $-7,11$ & $-0,57$ & $-6,54$ \\
\hline$C 4$ & 131,69 & 25,85 & 145,06 & 57,60 & 126,58 & 26,24 & 128,46 & 24,09 & 122,63 & 27,98 & 122,33 & 26,14 \\
\hline$\sigma$ & 4,55 & 216,10 & & & 1,90 & 50,84 & 1,90 & 52,42 & & & & \\
\hline$\omega$ & & & 0,95 & 14,87 & & & & & 0,797 & 10,03 & 0,83 & 10,11 \\
\hline$\alpha$ & & & 0,85 & 24,15 & & & & & 0,486 & 13,56 & 0,47 & 13,27 \\
\hline$\beta$ & & & 0,37 & 29,75 & & & & & 0,329 & 11,35 & 0,32 & 10,18 \\
\hline$\lambda$ & & & & & 0,11 & 11,09 & & & 0,049 & 4,51 & & \\
\hline$L 1$ & & & & & & & 0,087 & 5,21 & & & 0,037 & 2,92 \\
\hline$L 2$ & & & & & & & 0,070 & 4,60 & & & 0,037 & 2,68 \\
\hline$L 3$ & & & & & & & 0,028 & 2,93 & & & 0,027 & 2,60 \\
\hline$L 4$ & & & & & & & 0,264 & 10,07 & & & 0,125 & 4,66 \\
\hline$\mu$ & & & & & 8,09 & 7,82 & 8,00 & 7,82 & 7,01 & 3,55 & 6,80 & 4,46 \\
\hline$\sigma_{J}$ & & & & & 10,10 & 42,73 & 10,07 & 41,60 & 6,50 & 6,19 & 6,48 & 7,63 \\
\hline$\overline{\mathrm{LL}}$ & -6148.1 & & -5052.2 & & $\begin{array}{l}-5148.3 \\
\end{array}$ & & -5096.6 & & -4822.6 & & -4810.8 & \\
\hline $\mathrm{SC}$ & 12365,0 & & 10188,5 & & 10388,4 & & 10307,9 & & $\overline{9752,3}$ & & 9751,6 & \\
\hline
\end{tabular}


Table B.3: Estimation Results (AUSTRALIA (Victoria)).

\begin{tabular}{|c|c|c|c|c|c|c|c|c|c|c|c|c|}
\hline \multirow[b]{2}{*}{ Parameter } & \multicolumn{2}{|l|}{ Model 1} & \multicolumn{2}{|l|}{ Model 2} & \multicolumn{2}{|l|}{ Model 3} & \multicolumn{2}{|l|}{ Model 3b } & \multicolumn{2}{|l|}{ Model 4} & \multicolumn{2}{|l|}{ Model 4b } \\
\hline & Coeff. & t-stat. & Coeff. & t-stat. & Coeff. & t-stat. & Coeff. & t-stat. & Coeff. & t-stat. & Coeff. & t-stat. \\
\hline B0 & 31,64 & 15,02 & 18,99 & 60,72 & 26,95 & 35,61 & 26,63 & 35,84 & 24,22 & 41,70 & 25,27 & 44,51 \\
\hline$\phi$ & 0,47 & 49,27 & 0,57 & 45,04 & 0,55 & 57,48 & 0,54 & 56,18 & 0,61 & 30,98 & 0,61 & 31,09 \\
\hline$B 2$ & $-0,011$ & $-7,08$ & $-0,002$ & $-11,27$ & $-0,008$ & $-14,52$ & $-0,008$ & $-14,38$ & $-0,0062$ & $-14,63$ & $-0,0067$ & $-15,78$ \\
\hline$D 1$ & 6,82 & 5,53 & 2,13 & 9,23 & 5,20 & 10,08 & 5,07 & 10,02 & 3,17 & 9,94 & 3,30 & 10,20 \\
\hline$C l$ & 6,37 & 4,83 & 2,23 & 10,51 & 3,59 & 8,13 & 3,37 & 7,70 & 2,06 & 6,31 & 5,05 & 15,05 \\
\hline$C 2$ & 53,82 & 10,61 & 110,27 & 51,27 & 55,42 & 15,79 & 57,53 & 15,62 & 45,55 & 10,62 & 46,50 & 13,07 \\
\hline$C 3$ & 4,32 & 3,43 & 7,29 & 38,94 & 4,90 & 11,47 & 5,08 & 11,70 & 6,00 & 18,04 & 2,81 & 8,45 \\
\hline$C 4$ & 48,50 & 2,74 & 63,72 & 44,56 & 58,03 & 11,02 & 59,78 & 12,12 & 52,13 & 18,02 & 37,10 & 11,56 \\
\hline$\sigma$ & 18,18 & 256,26 & & & & & 7,81 & 50,78 & & & & \\
\hline$\omega$ & & & 2,31 & 7,06 & & & & & 3,23 & 6,51 & 3,72 & 7,01 \\
\hline$\alpha$ & & & 1,07 & 33,89 & & & & & 0,32 & 10,75 & 0,33 & 10,92 \\
\hline$\beta$ & & & 0,49 & 77,96 & & & & & 0,62 & 29,45 & 0,61 & 28,41 \\
\hline$\lambda$ & & & & & 0,07 & 9,14 & & & 0,019 & 4,86 & & \\
\hline$L 1$ & & & & & & & 0,141 & 6,49 & & & 0,030 & 2,59 \\
\hline$L 2$ & & & & & & & 0,048 & 4,01 & & & 0,015 & 2,35 \\
\hline$L 3$ & & & & & & & 0,031 & 2.81 & & & 0,006 & 1,18 \\
\hline$L 4$ & & & & & & & 0,099 & 5,95 & & & 0,021 & 2,88 \\
\hline$\mu$ & & & & & 29,73 & 3,86 & 28,84 & 3,95 & 64,03 & 1,90 & 66,83 & 1,68 \\
\hline$\sigma_{J}$ & & & & & 53,98 & 35,80 & 52,22 & 37,48 & 84,06 & 8,17 & 86,24 & 6,87 \\
\hline$\overline{\overline{\mathrm{LL}}}$ & $=8582.6$ & & -7566.8 & & -7527.5 & & -7512.7 & & $=-7161.7$ & & $=-7159.2$ & \\
\hline SC & 17228,2 & & 15210,6 & & 15139,0 & & 15130,4 & & 14421,4 & & 14447,4 & \\
\hline
\end{tabular}

Table B.4: Estimation Results (NEW ZEALAND (Hayward)).

\begin{tabular}{|c|c|c|c|c|c|c|c|c|c|c|c|c|}
\hline \multirow[b]{2}{*}{ Parameter } & \multicolumn{2}{|l|}{ Model 1} & \multicolumn{2}{|l|}{ Model 2} & \multicolumn{2}{|l|}{ Model 3} & \multicolumn{2}{|l|}{ Model 3b } & \multicolumn{2}{|l|}{ Model 4} & \multicolumn{2}{|l|}{ Model 4b } \\
\hline & Coeff. & t-stat. & Coeff. & t-stat. & Coeff. & t-stat. & Coeff. & t-stat. & Coeff. & t-stat. & Coeff. & t-stat. \\
\hline$B O$ & 43,94 & 36,25 & 44,72 & 64,25 & 45,47 & 48,16 & 44,77 & 43,97 & 46,82 & 112,15 & 46,82 & 112,93 \\
\hline$\phi$ & 0,62 & 47,94 & 0,61 & 23,70 & 0,64 & 45,22 & 0,65 & 42,54 & 0,57 & 22,89 & 0,57 & 22,67 \\
\hline$B 2$ & $-0,013$ & $-10,13$ & $-0,011$ & $-15,60$ & $-0,015$ & $-16,17$ & $-0,014$ & $-13,45$ & $-0,017$ & $-31,62$ & $-0,017$ & $-31,52$ \\
\hline$D 1$ & 3,35 & 5,05 & 3,25 & 6,53 & 2,44 & 4,36 & 2,77 & 4,67 & 2,83 & 9,56 & 2,82 & 9,57 \\
\hline$C l$ & $-4,05$ & $-6,48$ & $-5,69$ & $-15,26$ & $-5,27$ & $-10,10$ & $-4,91$ & $-8,43$ & $-4,57$ & $-15,12$ & $-4,53$ & $-14,97$ \\
\hline$C 2$ & 52,59 & 5,83 & 64,60 & 17,62 & 40,30 & 7,14 & 48,73 & 7,62 & 46,32 & 11,26 & 46,62 & 11,20 \\
\hline$C 3$ & $-2,50$ & $-3,82$ & 2,81 & 7,51 & 1,71 & 3,24 & 1,93 & 3,33 & $-1,07$ & $-3,38$ & $-1,03$ & $-3,26$ \\
\hline$C 4$ & $-5,17$ & $-0,72$ & $-120,29$ & $-30,96$ & 458,06 & 53,76 & 455,55 & 55,96 & 22,01 & 2,51 & 21,48 & 2,36 \\
\hline$\sigma$ & 9,87 & 91,25 & & & 5,43 & 17,64 & 7,35 & 29,44 & & & & \\
\hline$\omega$ & & & 8,14 & 9,42 & & & & & 1,11 & 3,60 & 1,13 & 3,64 \\
\hline$\alpha$ & & & 0,40 & 9,91 & & & & & 0,36 & 8,84 & 0,36 & 8,61 \\
\hline$\beta$ & & & 0,60 & 25,77 & & & & & 0,59 & 19,75 & 0,58 & 18,93 \\
\hline$\lambda$ & & & & & 0,42 & 10,71 & & & 0,10 & 5,76 & & \\
\hline$L 1$ & & & & & & & 0,066 & 1,88 & & & 0,096 & 3,40 \\
\hline$L 2$ & & & & & & & 0,169 & 3,61 & & & 0,114 & 3,17 \\
\hline$L 3$ & & & & & & & 0,279 & 5,03 & & & 0,089 & 2,89 \\
\hline$L 4$ & & & & & & & 0,171 & 3,58 & & & 0,145 & 3,71 \\
\hline$\mu$ & & & & & 0,99 & 1,21 & 1,64 & 0,99 & 2,97 & 1,44 & 2,92 & 1,49 \\
\hline$\sigma_{J}$ & & & & & 12,75 & 36,94 & 15,94 & 20,20 & 15,51 & 22,40 & 15,18 & 22,34 \\
\hline$\overline{\mathrm{LL}}$ & -5291.8 & & -5184.0 & & -5218.3 & & -5212.1 & & "-4984.4 & & -4983.6 & \\
\hline $\mathrm{SC}$ & 10649,0 & & 10447,9 & & 10523,8 & & 10533,2 & & 10070,5 & & 10090,7 & \\
\hline
\end{tabular}


Table B.5: Estimation Results (SPAIN).

\begin{tabular}{|c|c|c|c|c|c|c|c|c|c|c|}
\hline \multirow[b]{2}{*}{ Parameter } & \multicolumn{2}{|l|}{ Model 1} & \multicolumn{2}{|l|}{ Model 2} & \multicolumn{2}{|l|}{ Model 3} & \multicolumn{2}{|l|}{ Model 4} & \multicolumn{2}{|l|}{ Model 4b } \\
\hline & Coeff. & t-stat. & Coeff. & t-stat. & Coeff. & t-stat. & Coeff. & t-stat. & Coeff. & t-stat. \\
\hline$B O$ & 3,32 & 39,24 & 3,81 & 91,52 & 3,44 & 47,21 & 3,62 & 32,90 & 3,97 & 75,94 \\
\hline$\phi$ & 0,60 & 29,15 & 0,53 & 16,75 & 0,62 & 32,67 & 0,55 & 11,76 & 0,53 & 17,10 \\
\hline$B 2$ & 0,001 & 10,54 & 0,0004 & 5,86 & 0,0008 & 8,41 & 0,0006 & 4,51 & 0,0002 & 2,73 \\
\hline$D 1$ & 0,787 & 29,13 & 0,56 & 14,36 & 0,71 & 14,37 & 0,55 & 7,68 & 0,53 & 16,28 \\
\hline$C l$ & 0,18 & 3,26 & 0,15 & 4,94 & 0,16 & 3,46 & 0,13 & 2,07 & 0,17 & 5,79 \\
\hline$C 2$ & 70,98 & 4,58 & 72,57 & 12,87 & 49,14 & 3,07 & 44,28 & 1,68 & 90,70 & 8,29 \\
\hline C3 & $-0,43$ & $-8,33$ & $-0,16$ & $-4,99$ & $-0,36$ & $-7,92$ & $-0,25$ & $-4,54$ & $-0,12$ & $-3,87$ \\
\hline C4 & $-2129,3$ & $-639,3$ & $-2112,2$ & $-383,6$ & $-2123,6$ & $-591,4$ & $-2120,3$ & $-307,7$ & $-2110,9$ & $-267,4$ \\
\hline$\sigma$ & 0,67 & 58,26 & & & 0,52 & 20,14 & & & & \\
\hline$\omega$ & & & 0,018 & 6,66 & & & 0,034 & 1,95 & 0,002 & 0,80 \\
\hline$\alpha$ & & & 0,18 & 6,66 & & & 0,14 & 2,76 & 0,16 & 5,79 \\
\hline$\beta$ & & & 0,78 & 32,88 & & & 0,85 & 17,05 & 0,81 & 29,09 \\
\hline$\lambda$ & & & & & 0,193 & 3,58 & 0,0002 & 0,00 & & \\
\hline$L 1$ & & & & & & & & & 0,45 & 3,03 \\
\hline$L 2$ & & & & & & & & & 0,25 & 2,23 \\
\hline$L 3$ & & & & & & & & & 0,08 & 1,06 \\
\hline$L 4$ & & & & & & & & & 0,15 & 2,10 \\
\hline$\mu$ & & & & & 0,378 & 2,61 & 0,61 & 0,00 & $-0,18$ & $-2,16$ \\
\hline$\sigma_{J}$ & & & & & 0,919 & 11,49 & 0,41 & 0,00 & 0,50 & 8,26 \\
\hline$\overline{\mathrm{LLL}}$ & $-1107,9$ & & $\overline{-942,1}$ & & $-1077,8$ & & $-1010,3$ & & $\overline{-915,2}$ & \\
\hline SC & 2278,8 & & 1961,2 & & 2239,6 & & 2118,6 & & 1949,4 & \\
\hline
\end{tabular}

Table B.6: Estimation Results (PJM).

\begin{tabular}{|c|c|c|c|c|c|c|c|c|c|c|c|c|}
\hline \multirow[b]{2}{*}{ Parameter } & \multicolumn{2}{|l|}{ Model 1} & \multicolumn{2}{|l|}{ Model 2} & \multicolumn{2}{|l|}{ Model 3} & \multicolumn{2}{|l|}{ Model 3b } & \multicolumn{2}{|l|}{ Model 4} & \multicolumn{2}{|l|}{ Model 4b } \\
\hline & Coeff. & t-stat. & Coeff. & t-stat. & Coeff. & t-stat. & Coeff. & t-stat. & Coeff. & t-stat. & Coeff. & t-stat. \\
\hline B0 & 17,59 & 4,90 & 8,70 & 22,60 & 15,92 & 22,26 & 15,88 & 21,60 & 16,70 & 32,71 & 16,69 & 32,25 \\
\hline$\phi$ & 0,57 & 85,02 & 0,39 & 9,69 & 0,39 & 41,42 & 0,39 & 39,88 & 0,49 & 17,67 & 0,49 & 17,23 \\
\hline$B 2$ & 0,0072 & 2,32 & 0,0079 & 15,76 & 0,008 & 11,71 & 0,008 & 11,83 & 0,006 & 10,50 & 0,006 & 10,31 \\
\hline$D 1$ & 7,45 & 3,12 & 4,11 & 12,99 & 3,06 & 6,67 & 2,99 & 6,43 & 2,33 & 6,50 & 2,33 & 6,47 \\
\hline$C 1$ & 5,79 & 2,62 & 4,91 & 22,56 & 1,46 & 4,21 & 1,28 & 3,65 & 0,97 & 3,12 & 0,95 & 3,01 \\
\hline$C 2$ & $-68,75$ & $-6,38$ & $-128,08$ & $-84,34$ & $-91,41$ & $-12,99$ & $-95,33$ & $-11,69$ & 105,50 & 12,07 & 103,58 & 11,56 \\
\hline C3 & 5,61 & 2,38 & $-7,21$ & $-19,41$ & 2,05 & 5,78 & 2,12 & 6,09 & $-3,39$ & $-11,42$ & $-3,29$ & $-11,00$ \\
\hline C4 & $-733,18$ & $-22,36$ & 1452,43 & 777,25 & $-685,66$ & $-68,04$ & $-682,03$ & $-67,76$ & 556,72 & 101,39 & 557,43 & 98,16 \\
\hline$\sigma$ & 20,29 & 14,92 & & & 5,99 & 42,95 & & & & & & \\
\hline$\omega$ & & & 1,42 & 2,06 & & & & & & & 3,96 & 7,30 \\
\hline$\alpha$ & & & 1,117 & 16,80 & & & & & & & 0,31 & 9,80 \\
\hline$\beta$ & & & 0,498 & 27,02 & & & & & & & 0,56 & 25,67 \\
\hline$\lambda$ & & & & & 0,065 & 8,02 & & & 0,027 & 4,43 & & \\
\hline LI & & & & & & & 0,07 & 4,11 & & & 0,01 & 1,20 \\
\hline$L 2$ & & & & & & & 0,01 & 1,70 & & & 0,01 & 1,24 \\
\hline L3 & & & & & & & 0,02 & 1,85 & & & 0,03 & 2,41 \\
\hline L4 & & & & & & & 0,14 & 6,61 & & & 0,06 & 3,42 \\
\hline$\mu$ & & & & & 46,34 & 4,28 & 47,13 & 4,27 & 54,98 & 1,91 & 54,35 & 1,83 \\
\hline$\sigma_{J}$ & & & & & 65,81 & 13,37 & 67,00 & 12,66 & 67,05 & 4,94 & 66,67 & 4,50 \\
\hline$\overline{\mathrm{LLL}}$ & -6050.03 & & -5285.00 & & -4836.07 & & -4809.47 & & -4686.32 & & -4678.13 & \\
\hline SC & 12165,06 & & 10649,45 & & 9758,81 & & 9727,28 & & 9473,76 & & 9479,04 & \\
\hline
\end{tabular}


Table B. 7: Generalized Likelihood Ratio Tests * (p-values in parenthesis).

\begin{tabular}{|l|c|c|c|c|c|c|c|}
\hline Series & {$[1] \chi_{(2)}^{2}$} & {$[2] \chi_{(3)}^{2}$} & {$[3] \chi_{(5)}^{2}$} & {$[4] \chi_{(3)}^{2}$} & {$[5] \chi_{(2)}^{2}$} & {$[6] \chi_{(3)}^{2}$} & {$[7] \chi_{(3)}^{2}$} \\
\hline NordPool & 2748 & 656 & 2820 & 72 & 2164 & 24 & N.A. \\
& $(0.00)$ & $(0.00)$ & $(0.00)$ & $(0.00)$ & $(0.00)$ & $(0.00)$ & \\
\hline Argentina & 2191 & 1999,6 & 2651 & 459,2 & 651,4 & 103,4 & 23,6 \\
& $(0.00)$ & $(0.00)$ & $(0.00)$ & $(0.00)$ & $(0.00)$ & $(0.00)$ & $(0.00)$ \\
& 2031 & 2110 & 2841 & 810,2 & 731,6 & 29,6 & 5 \\
Australia & $(0.00)$ & $(0.00)$ & $(0.00)$ & $(0.00)$ & $(0.00)$ & $(0.00)$ & $(0.17)$ \\
(Vic toria) & & & & & & & \\
\hline New Zealand & 215,6 & 147 & 614,8 & 399,2 & 467,8 & 12,4 & 1,6 \\
(Hayward) & $(0.00)$ & $(0.00)$ & $(0.00)$ & $(0.00)$ & $(0.00)$ & $(0.006)$ & $(0.659)$ \\
\hline Spain & 331,6 & 60,2 & 195,2 & N.A. & 135 & N.A. & 190,2 \\
& $(0.00)$ & $(0.00)$ & $(0.00)$ & & $(0.00)$ & & $(0.00)$ \\
\hline PJM & 1530,1 & 2427,9 & 2727,4 & 1197,4 & 299,5 & 53,2 & 16,4 \\
& $(0.00)$ & $(0.00)$ & $(0.00)$ & $(0.00)$ & $(0.00)$ & $(0.00)$ & $(0.00)$ \\
& & & & & & & \\
\hline
\end{tabular}

\footnotetext{
* [1] Constant variance, no jump model against GARCH(1,1), no jump model; [2] Constant variance, no jump model against pure jump model; [3] Constant variance, no jump model against $\operatorname{GARCH}(1,1)$ jump $(\lambda)$ model; [4] GARCH(1,1) model against GARCH(1,1) jump $(\lambda)$ model; [5] Pure jump model against GARCH $(1,1)$ jump $(\lambda)$ model; [6] Pure jump model against jump $(\lambda(t))$; [7] $\operatorname{GARCH}(1,1) \operatorname{jump}(\lambda)$ model against $\operatorname{GARCH}(1,1)$ jump $(\lambda(\mathrm{t}))$ model. P-values are given in parenthesis.
} 


\section{REFERENCES}

Arranz, M. A., Escribano, A., and Mármol,F. (2000), "Effects of Applying Linear and Nonlinear Filters on Tests for Unit Roots with Additive Outliers", Working Paper 00-86, Statistics and Econometrics Series, Universidad Carlos III.

Bhanot, K. (2000), "Behavior of Power Prices: Implications for the Valuation and Hedging of Financial Journal of Risk, 2 , 43-62.

Bergstrom, A. R. (1988), "The History of Continuous-Time Econometric Models", Econometric Theory, 4:3, 365-383.

Berndt, E.K., Hall, B.H., Hall, R.E., and Hausman, J.A. (1974), "Estimation and Inference in NonLinear Structural Models”. Annals of Economic and Social Measurement, 4, 653-665.

Birnbaum, L., Del Aguila, J.Mª ., Domínguez, G., and Lekander, P. (2002), "Why Electricity Markets McKinsey Quarterly 1.

Bollerslev, T. (1986), "Generalized Autoregressive Conditional Heterokedasticity", Journal of Econometrics, 31, 307-327.

Bollerslev, T., Engle, R.F., and Nelson, D.B. (1994), "ARCH Models", in R.F. Engle and D.L. McFadden (eds.), Handbook of Econometrics, vol. 4, Amsterdam: Elsevier.

Bollerslev, T., and Ghysels, E. (1996), "Periodic Autoregressive Conditional Heteroscedasticity", Journal of Business and Economic Statistics, 14 , 139-151.

Borenstein, S. (2001), “The Trouble with Electricity Markets (and some Solutions)”, POWER Working Paper 081, University of California Energy Institute.

Boswijk, P.H. (2000), "Testing for a Unit Root with Near-Integrated Volatility", unpublished manuscript, Department of Quantitative Economics, Universiteit van Amsterdam.

Boswijk, P.H., and Doornik, J.A. (1999), "Distribution Approximations for Cointegration Tests with Stationary Exogenous Regressors”, Discussion Paper 99-013/4, Tinbergen Institute.

Carnero, A., Peña, D., and Ruiz, E. (2001), “Outliers and Conditional Autoregressive Heterocedasticity -07, Universidad Carlos III.

Carnero, A., Peña, D., and Ruiz, E. (2002), "Is Stochastic Volatility more flexible than GARCH?", WP 01-08, Universidad Carlos III.

Clewlow, L., and Strickland, C. (2000), Energy derivatives: Pricing and Risk Management, Lacima Publications.

Das, S.R. (2001), “The Surprise Element: Jumps in Interest Rate Diffusions”, Journal of Econometrics, $106,27-65$.

Das, S.R., and Sundaram, R.K. (1999), “Of Smiles and Smirks: a Term Structure Perspective”, Journal of Financial and Quantitative Analysis, 34 , 211-239.

De Vany, A. S., and Walls, D.W. (1999), “Cointegration Analysis of Spot Electricity Prices: Insights on Energy Economics, 21, 435-488. 
Review of Derivatives Research, 5 (1), 5-50.

Melino, A. (1994), "Estimation of Continuous-time Models in Finance", in Advances in Econometrics, Sixth World Congress, Volume II, edited by C. Sims, Cambridge University Press, Cambridge.

Neely, C. J. (1999), “Target Zones and Conditional Volatility: the Role of Realignments”, Journal of Empirical Finance, 6:2, 177-192. 
Nelson, D. B. (1990), "Stationarity and Persistence in the GARCH(1,1) Model”, Econometric Theory, 6, 318-344.

Ng, S., and Perron, P. (1998), "Lag Length Selection and the Construction of Unit Root Tests with Working paper 319, Boston University.

Nieuwland, F., Verschoor, W., and Wolff, C. (1994), "Stochastic Trends and Jumps in EMS Exchange Journal of International Money and Finance, 13, 699-727.

Pantula, S. G. (1989), "Estimation of Autoregressive Models with ARCH Errors”, Sankhya B, 50, 119138.

Peters, T.A. and Veloce W. (1998), "Robustness of Unit Root Tests in ARMA Models with Generalized ARCH Errors", unpublished manuscript, Brock University.

Pindyck, Robert S. (1999), "The Long-Run Evolution of Energy Prices”, The Energy Journal, 20, 1-27.

Pirrong, C., and Jermakyan, M. (1999), "The Price of Power: The Valuation of Power and Weather Derivatives", unpublished manuscript, Olin School of Business, Washington University.

Schwartz, E. (1997), "The Stochastic Behavior of Commodity Prices: Implications for Valuation and Hedging", Journal of Finance, 52, 923-973.

Schwartz, E., and Smith, J.E. (2000), "Short-Term Variations and Long-Term Dynamics in Commodity Prices", Management Science, 46, 893-911.

Verhoeven, P., and McAleer, M. (2000), "Modelling Outliers and Extreme Observations for ARMAGARCH Process", unpublished manuscript.

Vlaar, P., and Palm, F.C. (1993), "The Message in Weekly Exchange Rates in the European Monetary System: Mean Reversion, Conditional Heterokedasticity and Jumps", Journal of Business and Economic Statistics, 11, 351-360.

Vogelsang, T.J. (1999), “Two Simple Procedures for Testing for a Unit Root when there are Additive Journal of Time series Analysis, 20, 173-192.

Wolak, F. (1997), "Market Design and Price Behavior in Restructured Electricity Markets: an International Comparison", working paper, available at www-leland.stanford.edu/ wolak. 